\title{
الزمن والتشكيل الصوري في شعر ابن دراج
}

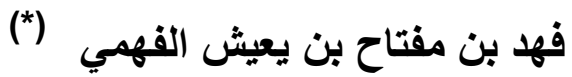

بسم الله الرحمن الرحيم

الحمد لله رب العالمين، والصلاة والسلام على أشرف المرسلين، وخاتم النبيين، ورحمة الله للعالمين، سيدنا محمد بن عبد الله، وعلى آله وصحبه

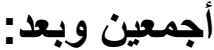

إن الأندلس تحتل مكانة في قلوب المسلمين، وذللك لأنها بينت القدرة لدى الأى المسلمين، في بلوغ الحضارة والازدهار، والانفتاح على الحضارات الأخرى،

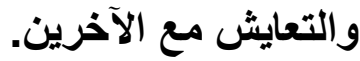
ويزخر الأدب الأندلني بالأعلام المجيدين ذوي الإنتاج الغزير والإبداع

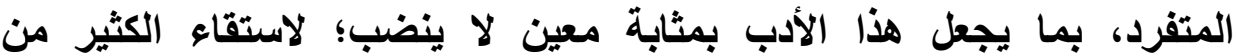

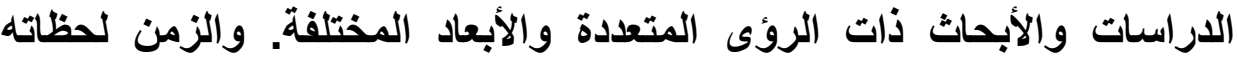

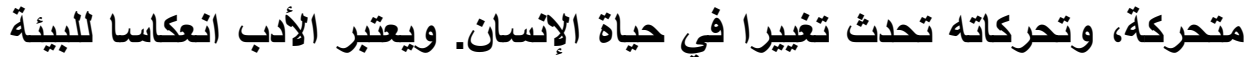

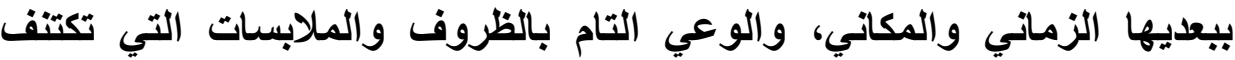
الثناعر حال إبداعه لقصيدته، ومن هنا تأتي أهمية دور الزمان الفيان بوصفه مكونا من مكونات التجربة الإبداعية.

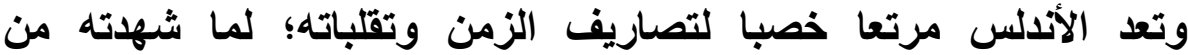

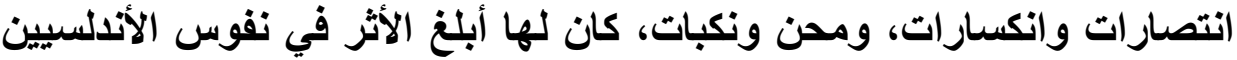
بصفة عامة، والثعراء منهم بصفة خاصة وانئ. و للزمن تأثير على إبداع الثعراء فجاء ترجمة لآلامهم وآمالهم، ومثل هذاء

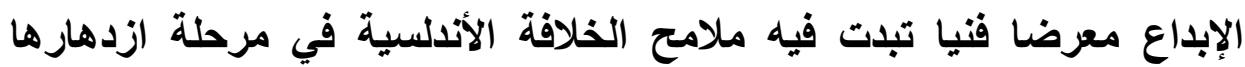

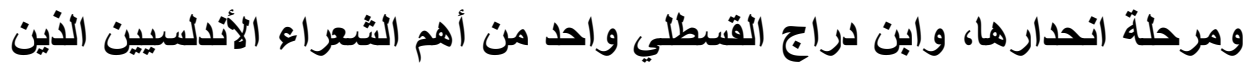

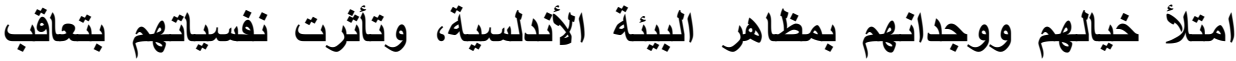
الأحداث عليها، هذا إلى جانب الثراء الفني لشعر ابن دراج القسطلي.

باحث دكثور اه بقسم اللغة العربية - جامعة الملك عبد العزيز - المملكة العربية السعودية. 
ولعل ما يعزز اختيار هذا الشاعر تحديلا ـ ابن دراج القسطلي ـ لاراسة تلك التك

الظاهرة الأدبية المهمة في شعره - الزمن- هو أن الظروف الاجتماعية والسياسية التي شهاها عصر ابن دراج حرمته من أن ينعم بالاستقرار في الإنه

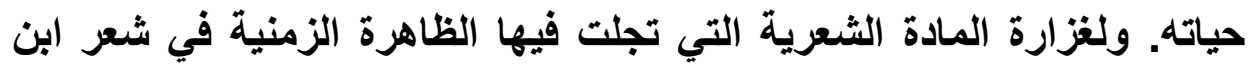

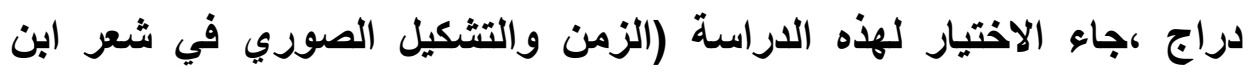
دراج)؛ وذلك لمعرفة حضور الزمن وعلاقته بالصورة في شعره.

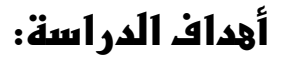

1-الوقوف على الدلالة الزمنية في شعر ابن دراج.

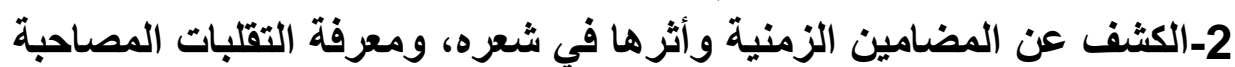
لحياته.

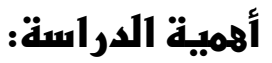

• أن الزمن بمثابة الحركة المستمرة في حياة الإنسان. • أن ألفاظ الزمن في شعر ابن دراج تقربنا أكثر لمعرفة شخصيته ونفسيته.

أن الزمن مرتبط بمفهوم الإنسان للحياة ،وهو الأي يحمل بؤس

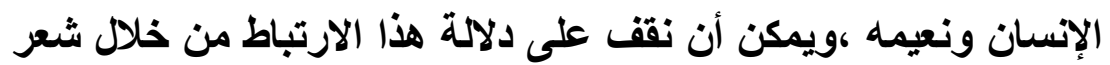
ابن دراج.

أن الزمن في شعر ابن دراج يصور لنا طبيعة الحياة في العصر الأندلسي.

$$
\begin{aligned}
& \text { أسئلة البــن } \\
& \text { • ما دلالة الزمن في شعر ابن دراج؟ } \\
& \text { • كيف حضرث مضامين الزمن في شعره؟ }
\end{aligned}
$$

الدراسات السابقةة: يمكن رصد بعض الأبحاث والدراسات التي تناولت هذه القضية بشكل جزئي

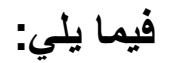


رسالة ماجستير بعنوان) الزمن في شعر ابن حمديس الصقلي( للباحث ختام

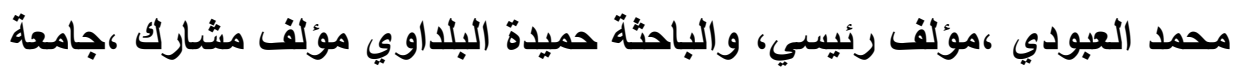
بغداد ، 2002م.

وجاءت الرسالة في تمهيد وثلاثة فصول ،في التمهيذ مفهوم الزمن، والزمن

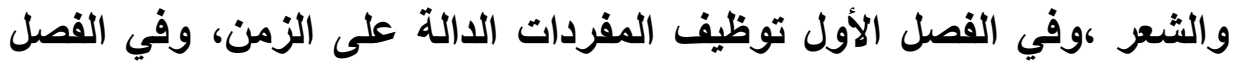
الثاني مواقف الثاعر من الزمن، ومن ثم الدراسة القنية في الفصل الثالث.

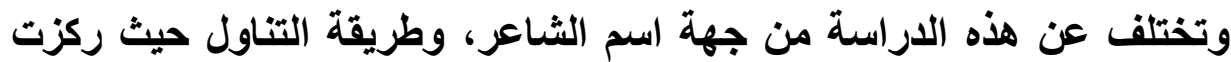

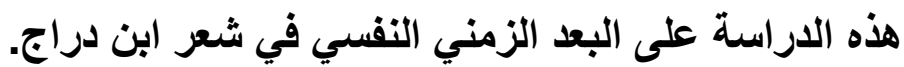

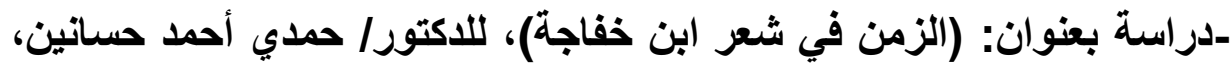

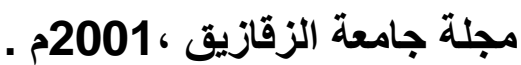

وتحدث عن العلاقة بين الثعر والزمن، والعوامل المؤثرة في رؤيته، والمواضيع التي نظم فيها شعره، وإحساسه بالمراحل الزمنية. وهذه الدراسة تختلف من حيث اسم الشاعر، وطريقة التناول. -رسالة ماجستير بعنوان:( الزمن في الشعر الأندلسي في عصر الطن الطوائف)،

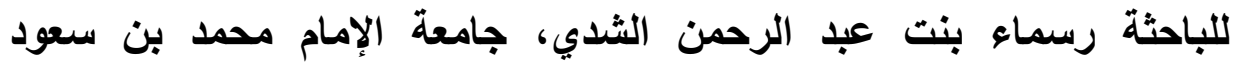

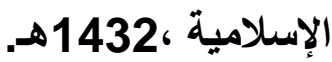

وجاءت الرسالة في تمهيذ وفصلين وخاتمة، وتثاولت في التمهيد مفهوم الزمن وتاريخ عصر الطوائف، وفي الفصل الأول تناولت تحولات الزمن، والفصل

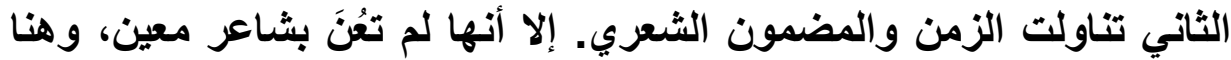
يتضح الاختلاف عن هذه الاراسة. -رسالة ماجستير بعنوان ( الحنين والغربة في الثعر الأندلسي، عصر سيادة غرناطة: 635 - 897هـ)، للباحثة مها روحي إبراهيم الخليلي، جامعة النجاح الوطنية فلفطين، 2007م.

وجاءت رسالة الباحثة في تمهيد وفصلين وخاتمة، تناولت في التمهيد الإطار السياسي والجغرافي والاجتماعي والفكري في عهد بني الأحمر، وجاء الفصل واهل

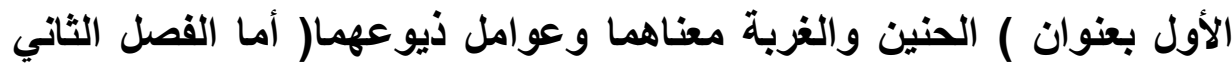


فكان بعنوان معاني شعر الحنين والغربة وسماته القنية، والخاتمة جاءت بأهم النتائج التي توصلت إليها الباحثة. وقد تناولت الحنين والغربة في فترة زمنية معينة ولم تركز في دراستها على فئل شاعر معين خلال فترة الدراسة كما أنها لم تشر لتأثير الزمان فئه وفي الثعر.

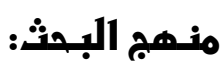
سيعتمد البحث في تحليله لشعر ابن دراج على المنهج الوصفي، كما سيستفاد من المنهج السيميائي، والمنهج النفسي، للوصول إلى استخلاص البعد النفسي في شعر ابن دراج.

\section{- الز من والنتشكيل الموري:}

تشكل الصورة عنصرا مهما من عناصر العمل الأدبي؛ لما تحمله من خيال

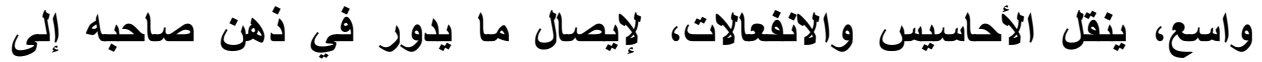

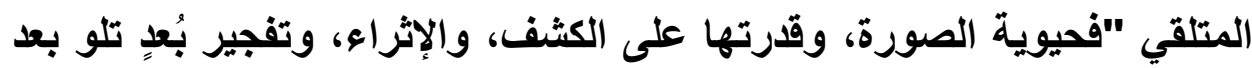

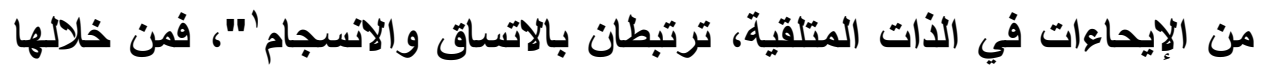
يستطيع المتلقي معايشة تلك المشاهد، والأحداث الزمنية، التي يهدف الثاتِ الثاعر

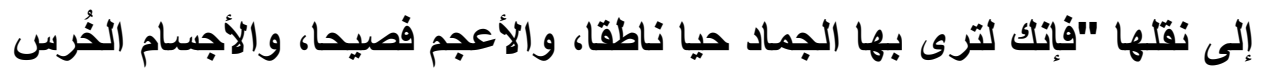

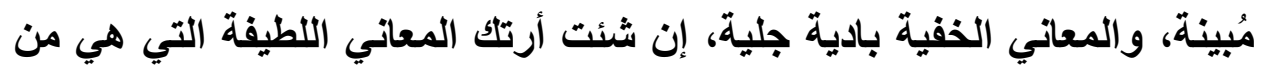

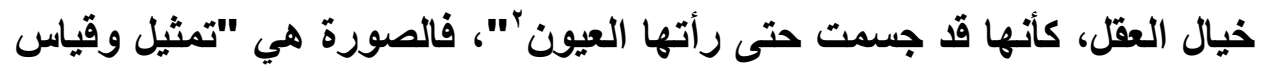

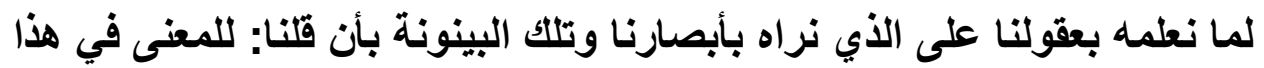

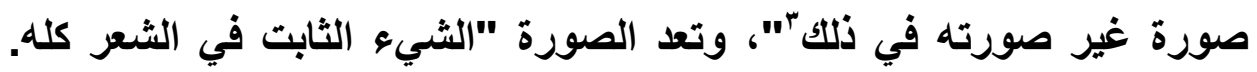

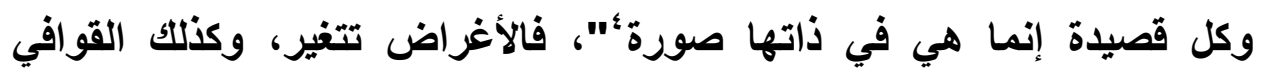
والأوزان، والأسلوب، بينما تجد الصورة راسخة "إنها قاعدة حياة الشعر

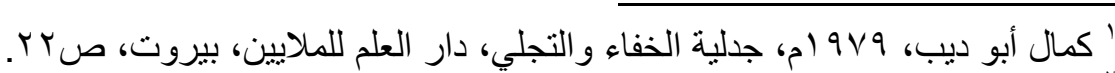

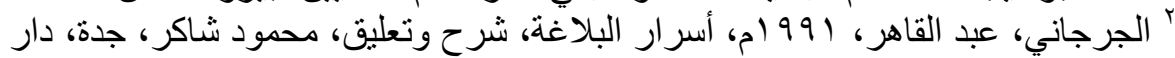

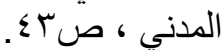

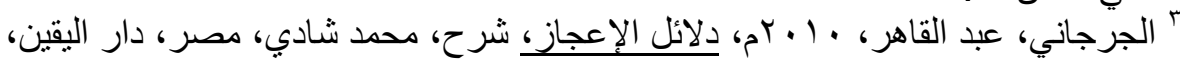

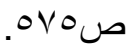
؛ اللغة الفنية، تعريب وتقديم، د. محمد حسن عبدالله، دار المعارف، القاهرة، صهء. 
والمحك الرئيسي للشاعر ومناط تألقه" ، وتعتبر الصورة "رسمٌ قوامه الكلمات، وقد لامسته صفة حسية. ويراد بالحسية في تشكيل الصورة، إجلاء أو تجلية الجانب البصري من الحسي. فبراعة المحاكاة أن يقدم الثيء محسوسا للعين كأنها تراه " لذلك فالصورة تقوم على " التركيب القائم على الإصابة في التنسيق القني الحي لوسائل التعبير التي ينتقيها وجود الثاعر ـأعني خواطره ومشاعره وعواطفهـ المطلق من عالم المحسات ليكثف عن حقيقة المشهر أو المعنى في

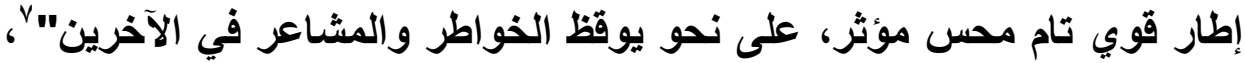

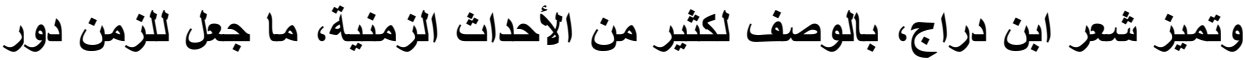
في تشكل الصورة في شعره:

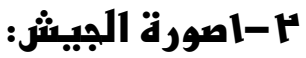
أعطت ملازمة ابن دراج لبعض الحكام في الأندلس، ومرافقته لبعضهم، أثناء الغزوات، تكوين مشه لما يراه، سواء لأعداد الجيوش، أو لسير المعارك، وكان

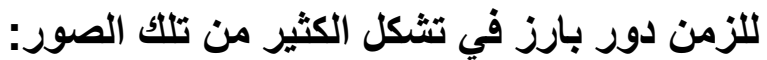
بخرق الملا كسف من الليل أو جنح

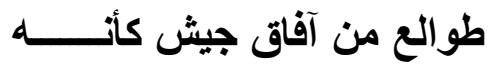

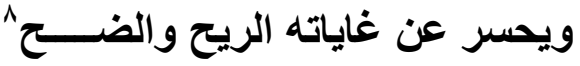
يضل مدى الأبصار في جنباته يشبه الشاعر جيش المنصور بن أبي عامر بالظلام؛ لكثرته، فالتشبيه: "الدالائة

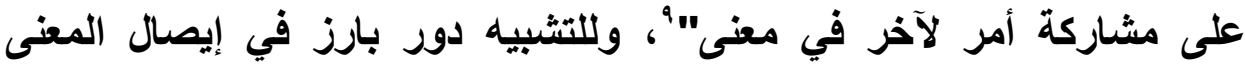

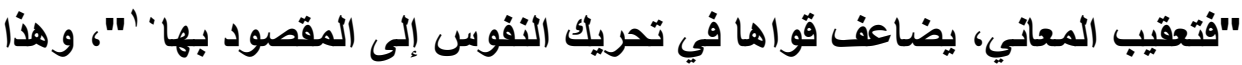
ما تجلى في قول ابن دراج:( كسف، جنح)، فشبه قدوم الجيش بقدوم الليل حينما

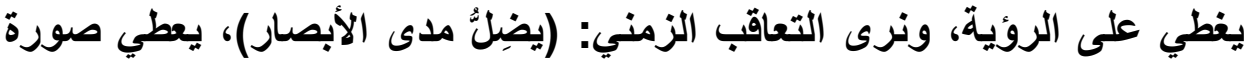

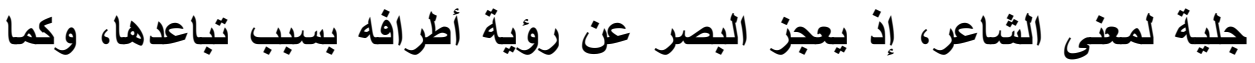

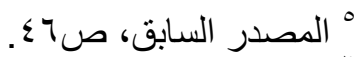

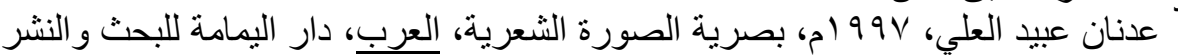

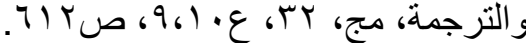

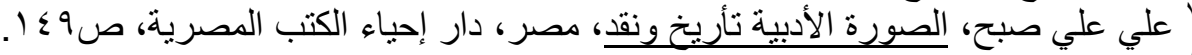

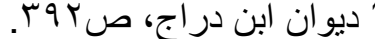

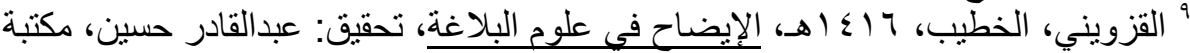

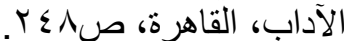
'. 'الصعيدي، عبد المتعال، بغية الإيضاح لتلخيص المفتاح، مكتبة الآداب، القاهرة، طل ا، 
أعجز الأبصار لكثرته، فقد أعجز ضوء الشمس فيما يصل إليه، تأكيلا على غايته

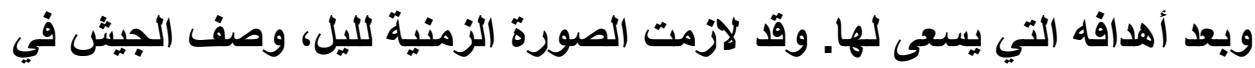
كثير من قصائده:

وأنت الأي أوردت "لونة" قاهرا خيولا سماء الأرض فيها نحورها

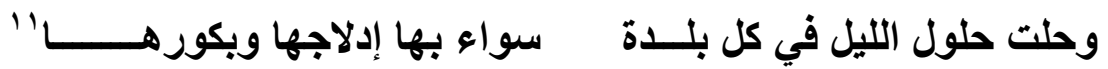

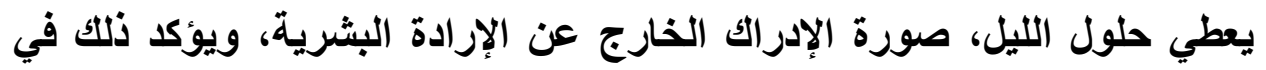

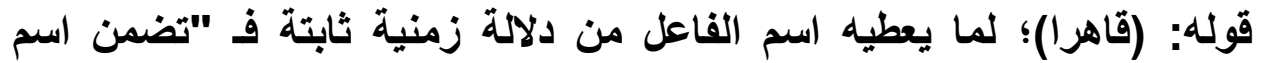
الفاعل خصائص الأسماء والأفعال جعلته قابلا ومعطاء للتعبير عن كل ما يتصل دلاءله

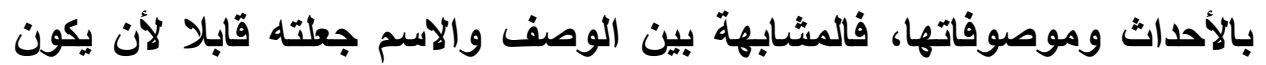

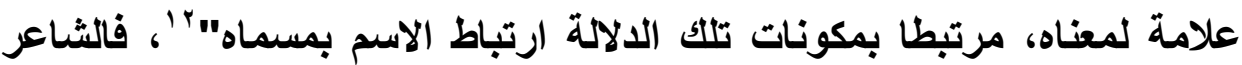
حينما شبه حلول الجيش بحلول الظلام، فهو الحلول الأي لا مفر منه، ولا وسيلة لمقاومته، وهذا ما جعله يؤكد ذلك في قوله: (سواء بولهاء بها إدلاجها وبكورها)، فالإدلاج والبكور، بيزهما مساواة تمثلت في الظلام، من خلاول حرف فوله العطف: (

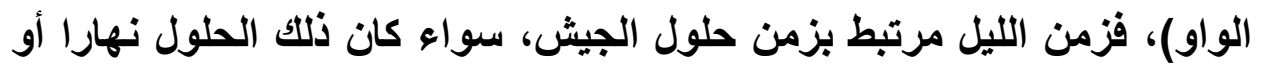
ليلا. وحضور الزمن الليلي كثيرا ما يربطه ابن دراج بوصفه التهن للجيش:

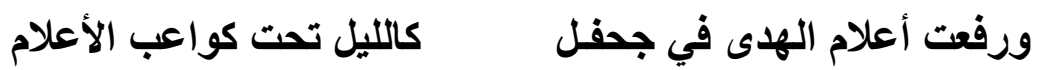
تعطي الصورة الزمنية، عدة دلالات عمد الشاعر إلى تصويرها، فشبه الجيش

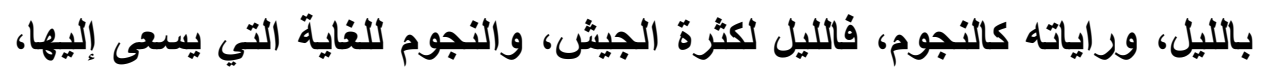

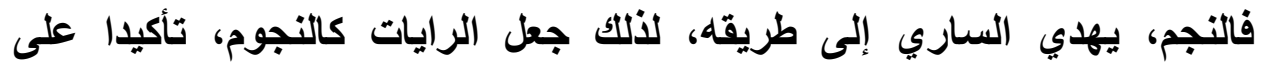

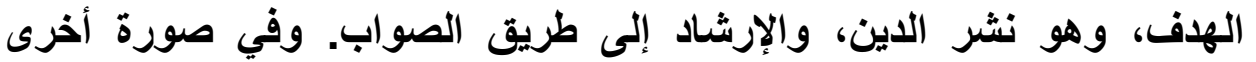
للجيش يشبهه بالقلك:

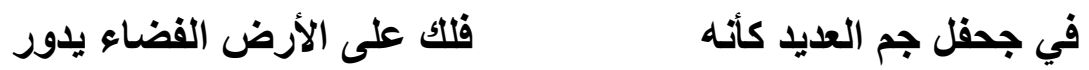
تبين الصورة الزمنية المتمثلة بالقلك، من خلال دورانه، التفاف الجيش وإحاطته

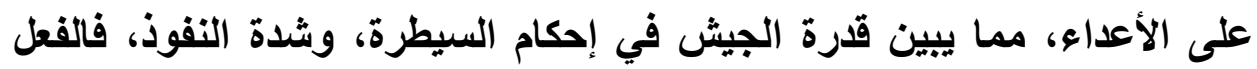

$$
\begin{aligned}
& \text { "' ديوان ابن دراج، تحقيق، محمود علي مكي، طا، (197 1، منشور ات المكتب الإسلامي، }
\end{aligned}
$$

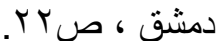

$$
\begin{aligned}
& \text { و'با عبد السلام بن عبد الرحمن العوفي، دلالات اسم الفاعل واستعمالاته، مجلة مركز بحوث }
\end{aligned}
$$

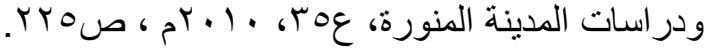


المضارع: ( يدور )، يعطي دلالة زمنية، مفادها الحركة، من خلال الدوران المتكرر. وفي تصوير آخر: النئ كتائب تعتام النفاق كأنها

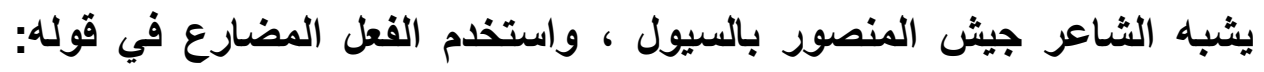

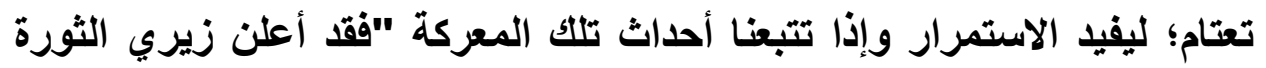

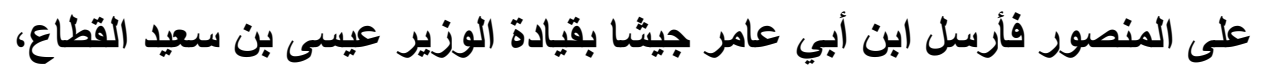

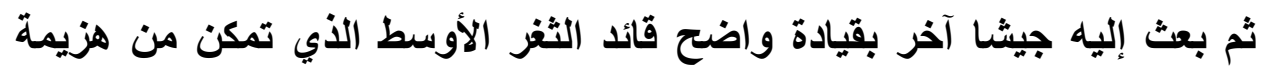

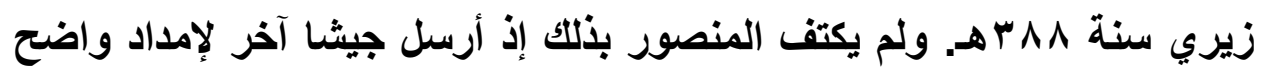

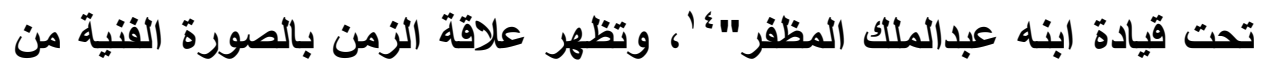

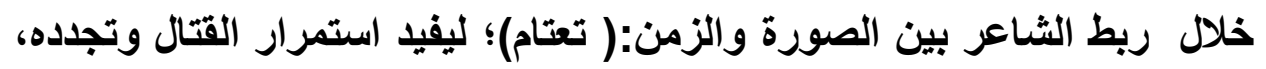
وقد بين التشبيه ما يريد إيصاله الثاعر إلى المتلقي، فمن أسباب تأثير التشبيه التئيه

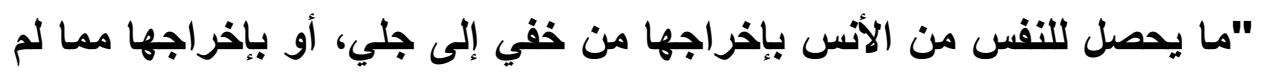

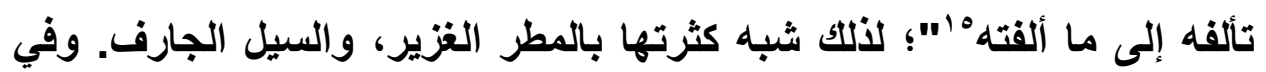

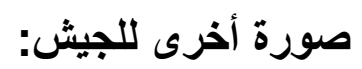

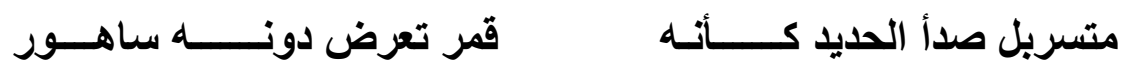

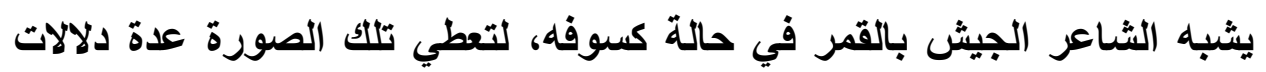

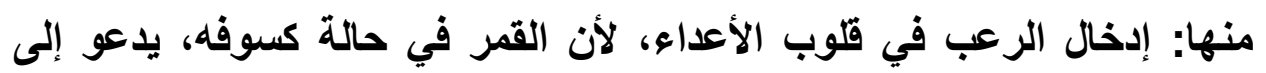

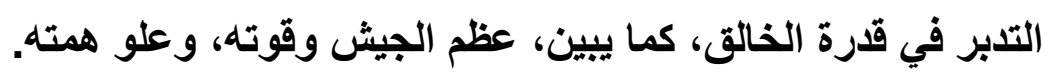

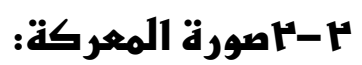

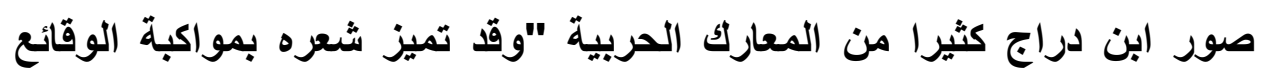

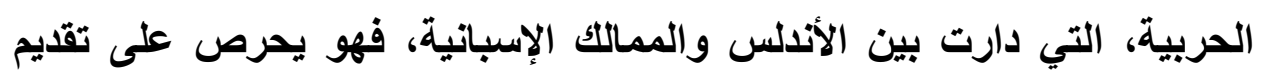

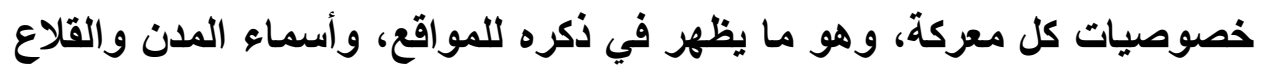

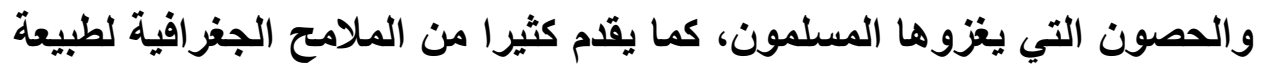

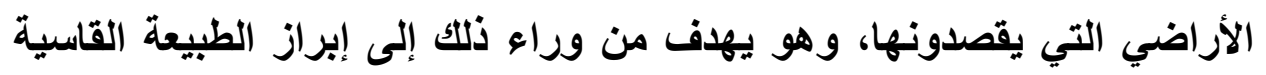

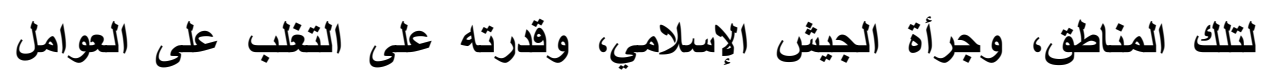

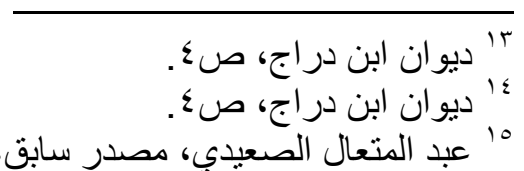

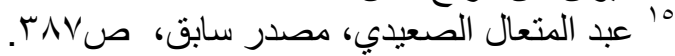


الطبيعية والبشرية معا لانتزاع التصر "'"، وسنعرض بعض الصور التي أوردها

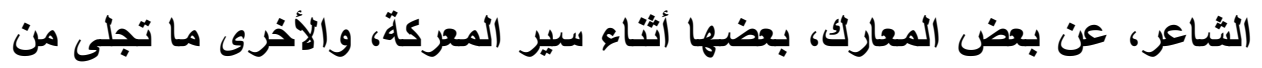

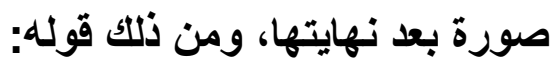

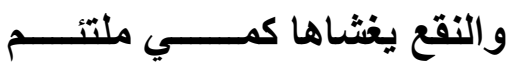

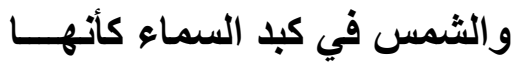
تبين الدلالات الزمنية شدة المعركة، وضراوة القتال فيها، فحين تكون الثمس فئس

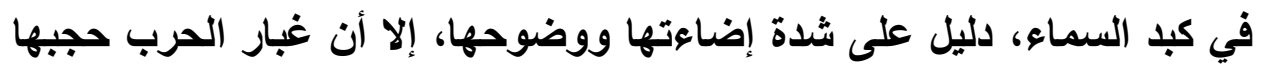

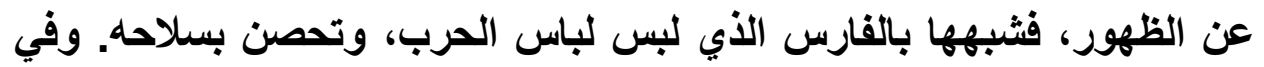
صورة أخرى لسير المعركة:

لمحا بنار المشرفية مُوقَّـــا

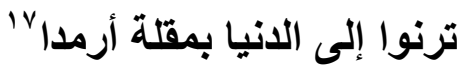

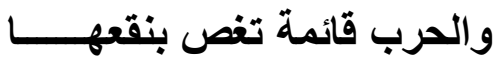
والشمس حيرى في السماء كأنها

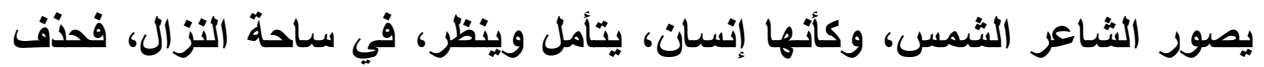
المشبه به، وأتى بشيء من صفاته، وهو المقلة، على سبيل الاستعارة المكنية،

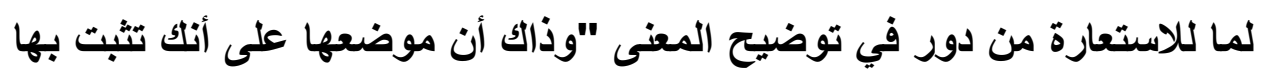

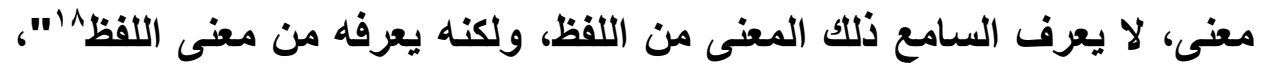

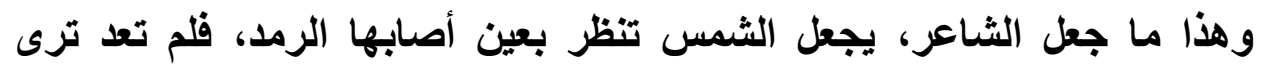

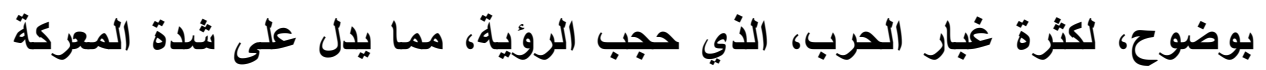

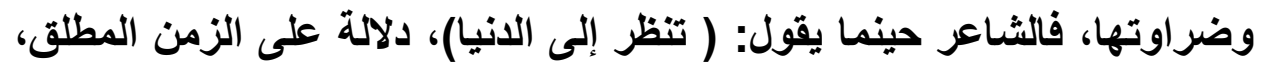

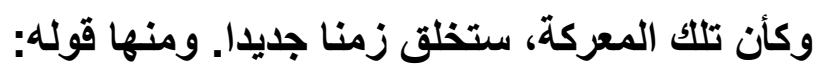

وغالت صدور الدارعين صدورها

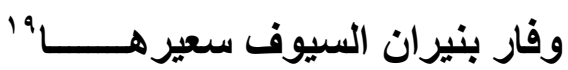

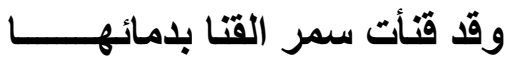
صليت وقد أذكى الطعان وقودها تعطي الأفعال(قنأت، صليت، فار) صورة للمعركة "وشأن الفعل أن يثبت المعنى

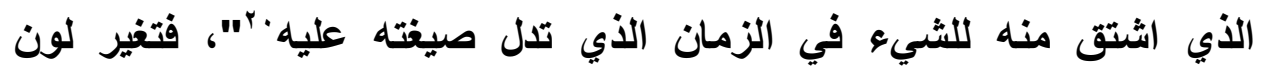

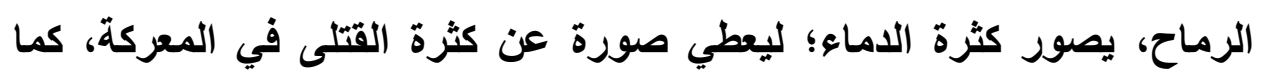

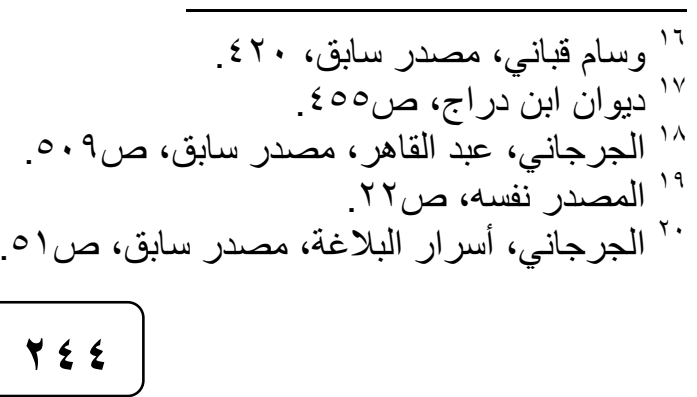


تبين الأفعال( صليت، فار) شدة المعركة وضراوتها، التي شبهها الثاعر بالنار،

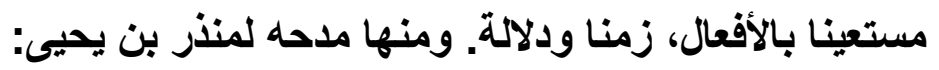

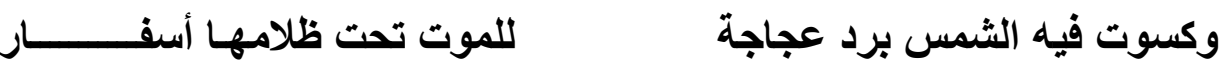

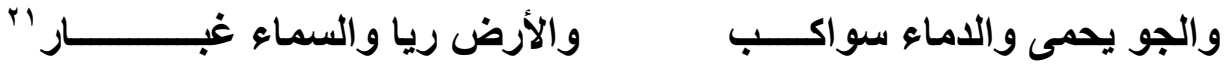

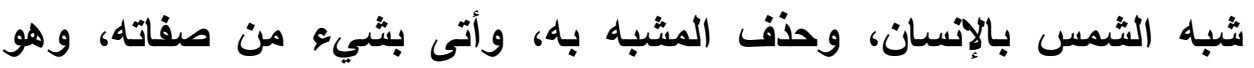

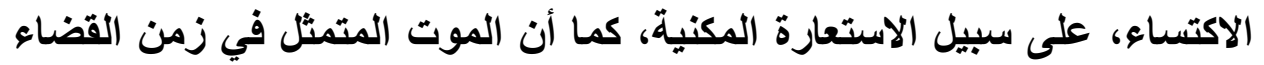

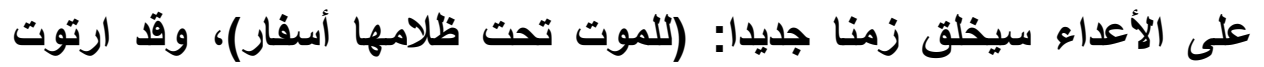

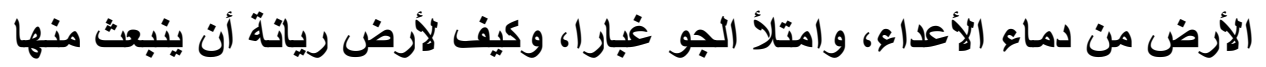

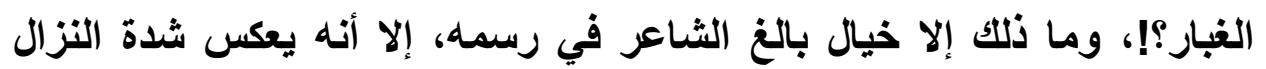

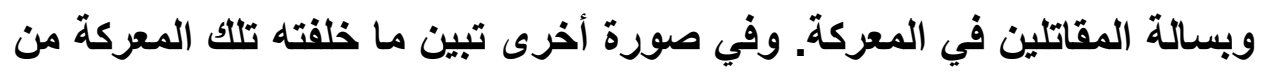

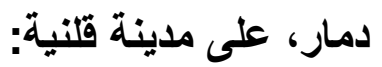

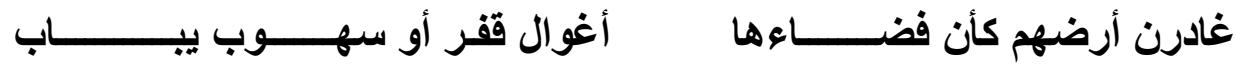

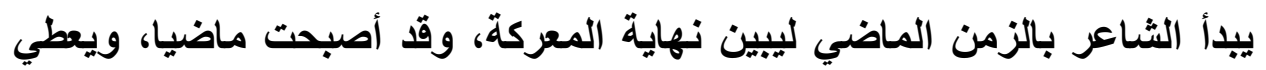

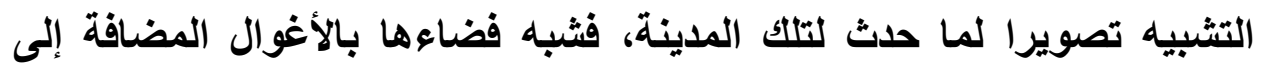
القفر، فقد أصبحت مدينة قلنية أرض موحشة خالية، تعكس ما حل بها لتها من دمار

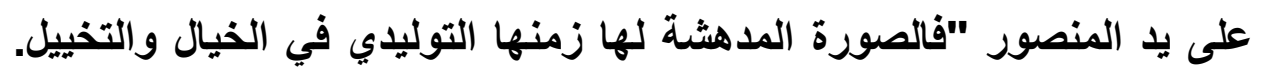

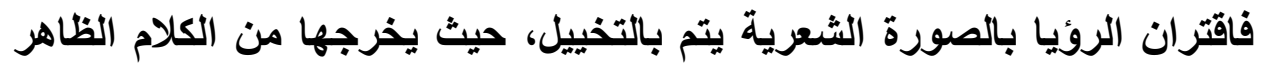

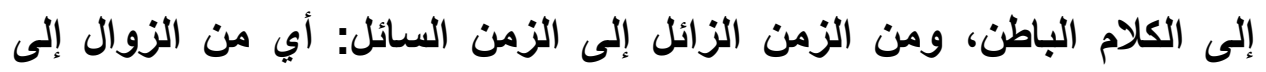

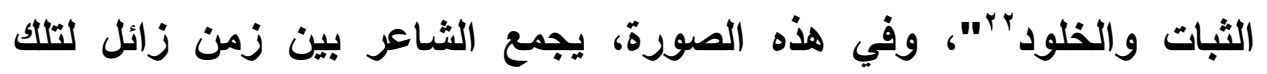

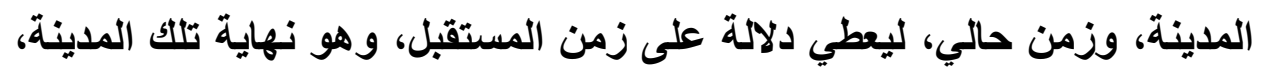

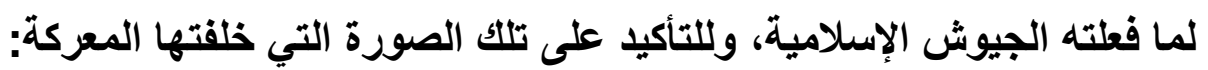

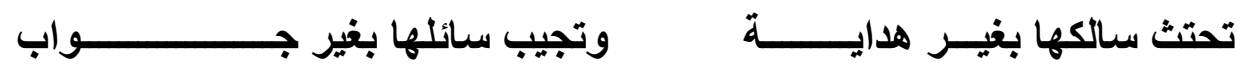

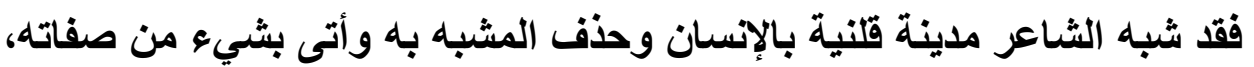

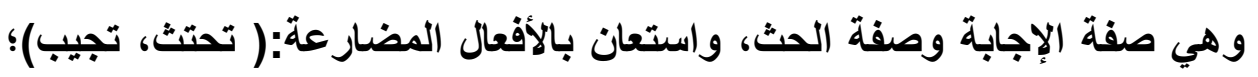

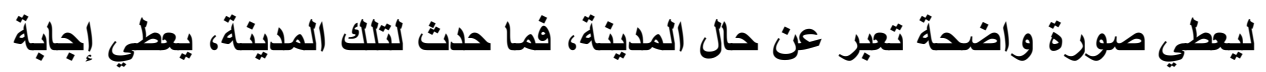

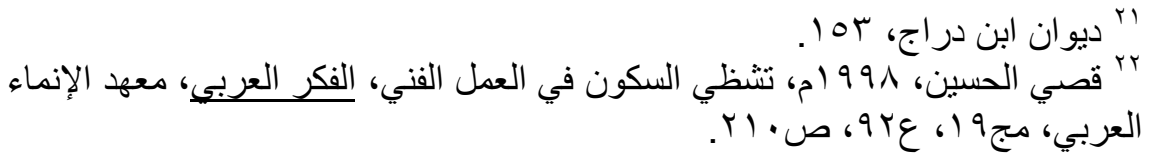


دون سؤال لها أو جوابا منها، فالزمن الحالي للمدينة من خلال تلك الصورة،

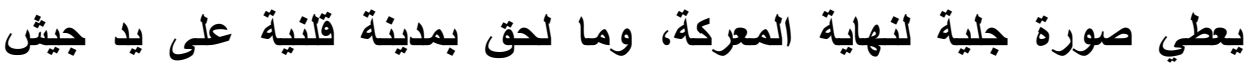
المنصور.

\section{|l-عصورة الممدوح:}

حظي المدح باهتمام ابن دراج، إذ بلغ أكثر من ثلثي ديوانه، ولا غرابة في ذلتك،

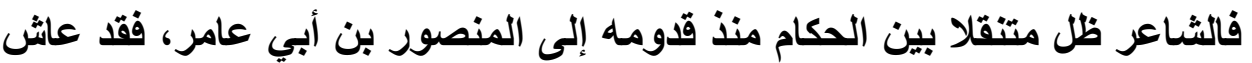

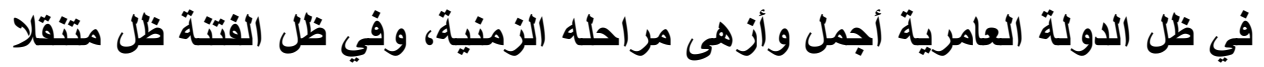

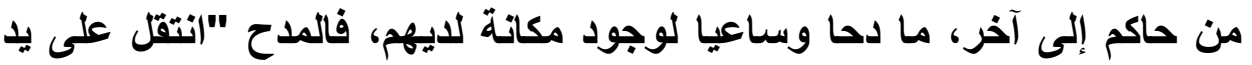

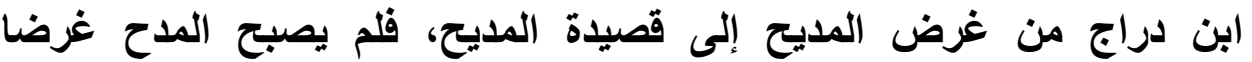

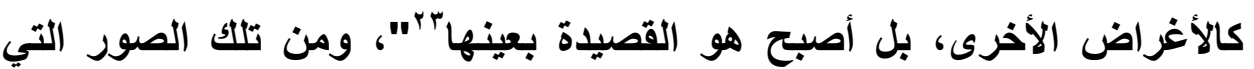
تجلى الزمن في تشكيلها:

كالثمس يحسر دونها إبصار ها

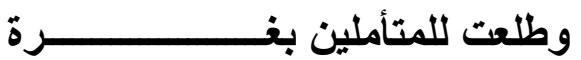
يحضر الزمن في تشكيل الصورة، لتعطي العلاقة بينهما، دلالة على قوة المشبه وهيتئه، فالنظر إلى الثمس، لا يستطيع الإنسان إطالته، وكذلك المنصور من

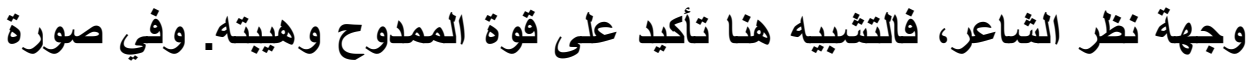

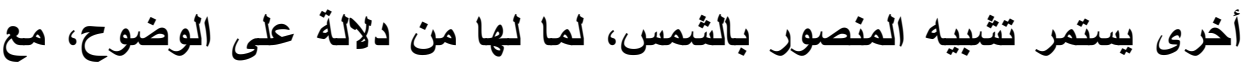
اختلاف المعنى الالالي للصورة في هذا السياق، عن معناها في الصورة الأولى:

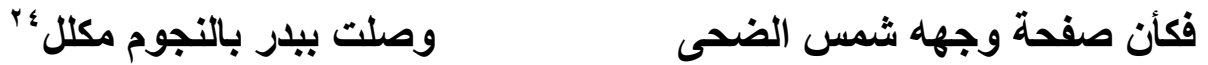
يبدي الشاعر تفاؤله بلقائه للمنصور، ويشبهه بالثمس؛ دلالية على جلاء همومه

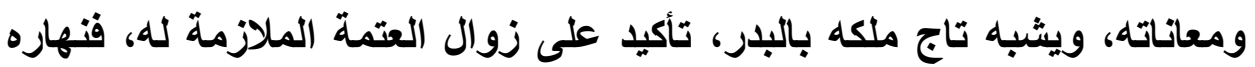

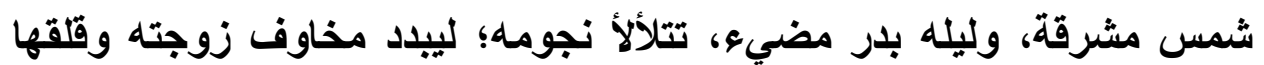

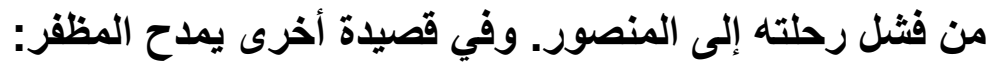
فظلهم حتما بنورك زائل المظزء

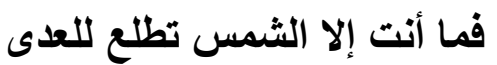

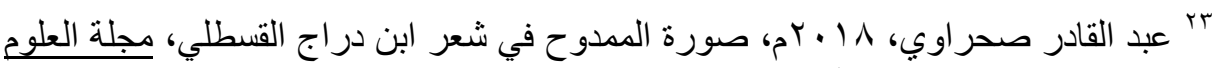

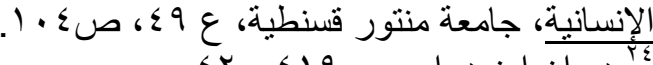

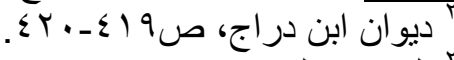

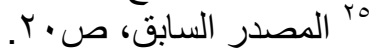


يعطي تثبيه الممدوح بالثمس، دلالة على وضوح هدف المداوح، ودحر

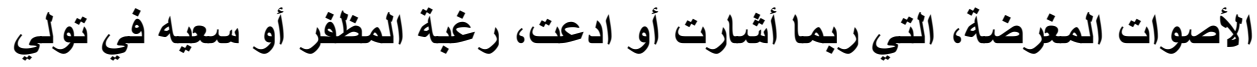

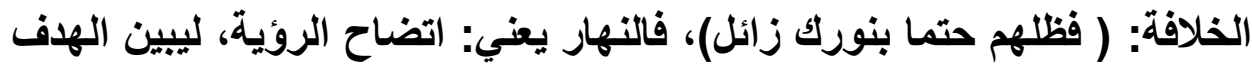

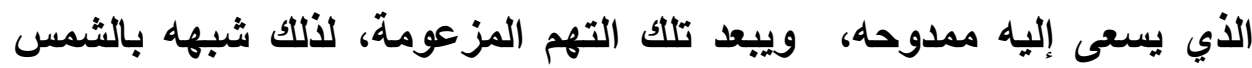

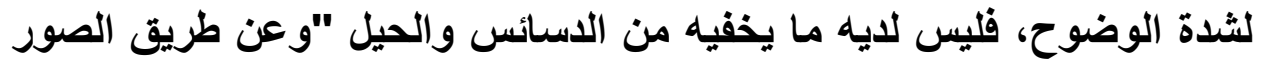

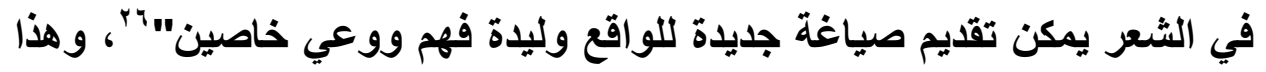

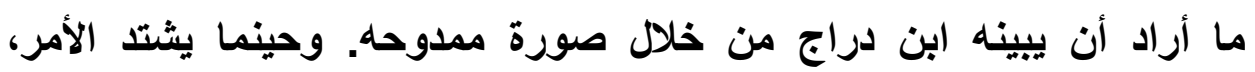

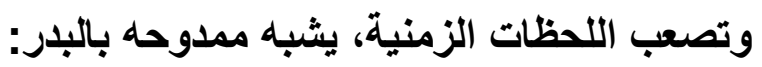

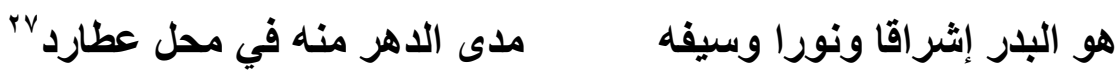

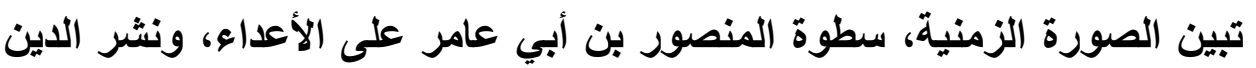

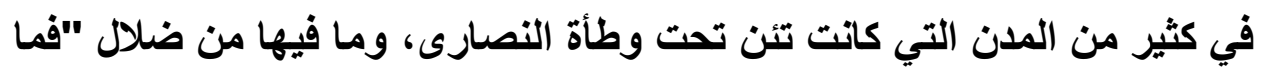

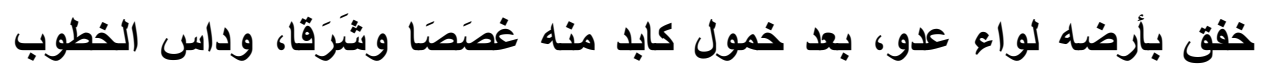

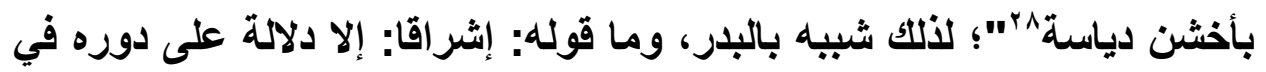

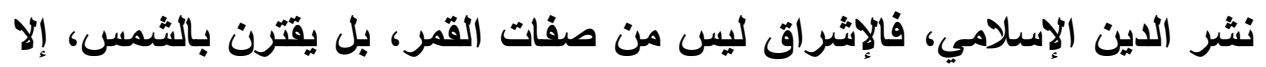

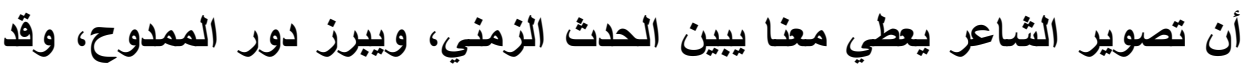

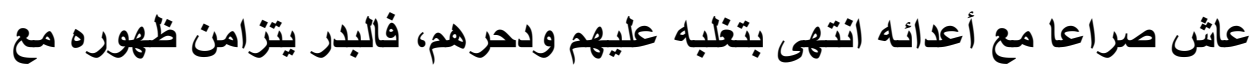
زمن الليل، وهنا يتجلى معنى الثاعر وهدفه في رسم صورة الثهابه المددوح. وفي

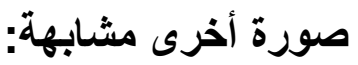

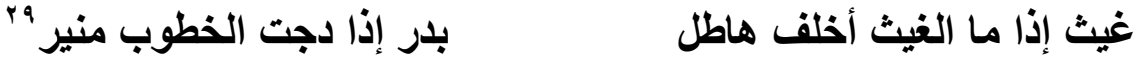
يقرن الثاعر صورة البدر بمواقف الثدة؛ لما له من دور في إزاحة الظلام

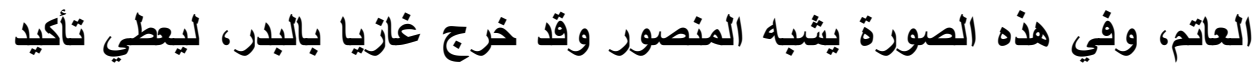

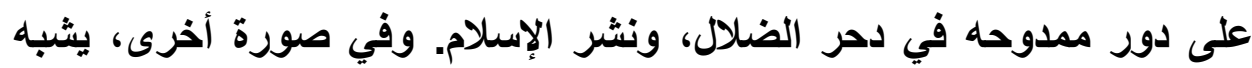
الناصر بالبدر لاوره في غزوة شنت دئ ياقب:

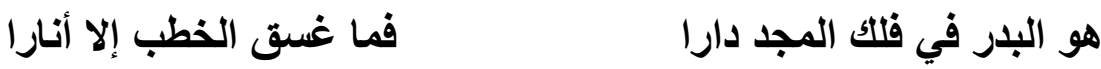

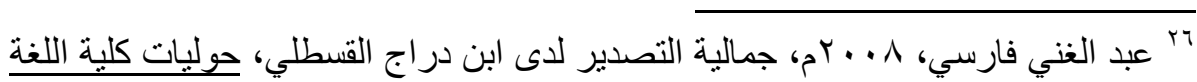

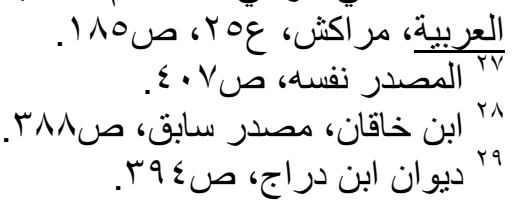


يشيد الشاعر بلدور الناصر في غزوة شنت ياقب، بعد أن كادت تقهر الجيوش

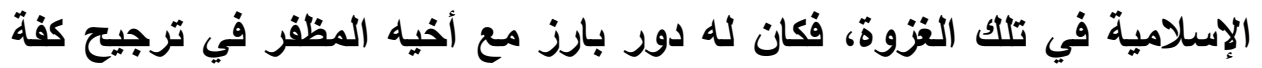

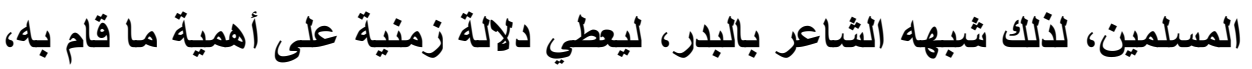

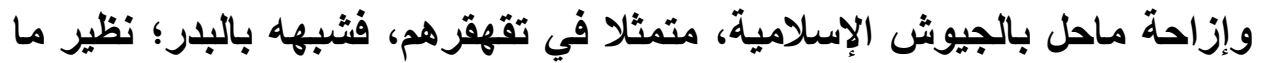

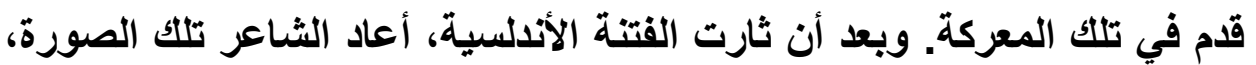

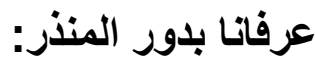

كالبلار مشرقة منه مطالعه ومشهر للمصلى قد طلعت به اله

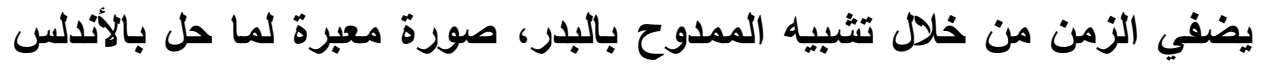

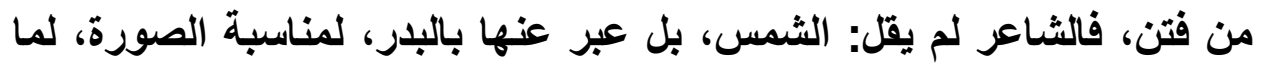

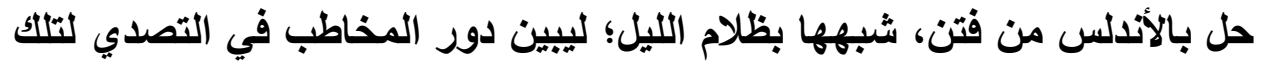
الفتن، وقد عاثت سرقسطة استقرار أمني في ظل المنذر بن يحيى، بينما كاتت

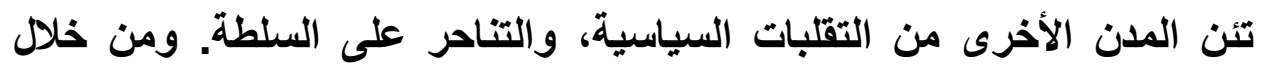

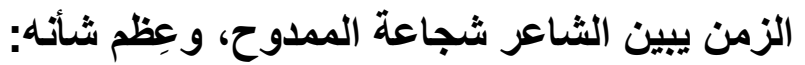

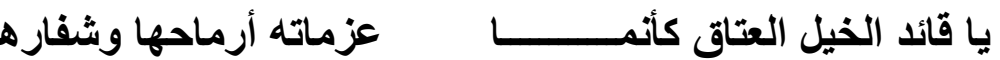

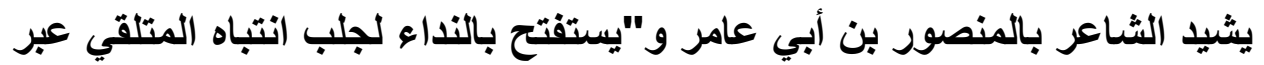

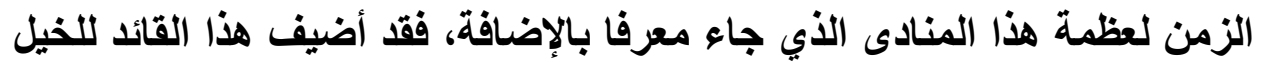

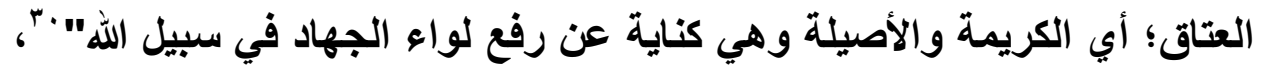
كما وظف الزمن من خلال التصوير، ليعطي دلالة على صلاح الحاكم:

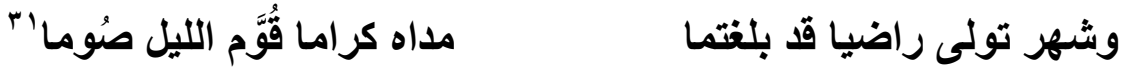

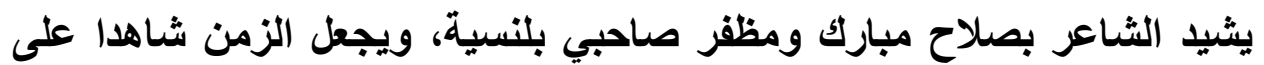

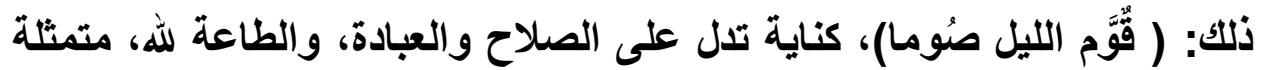

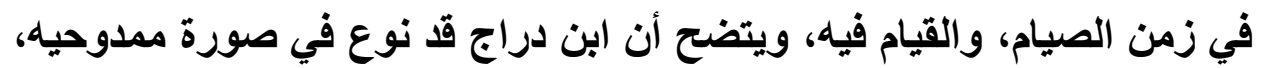

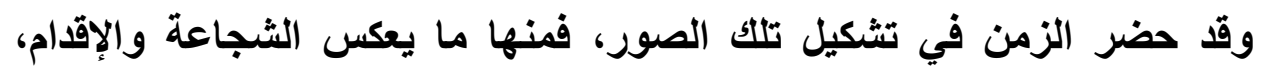

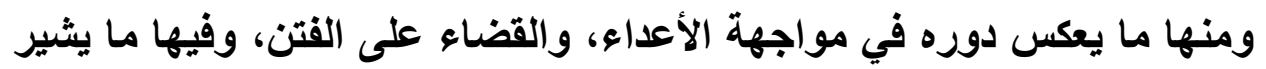

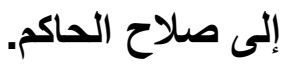

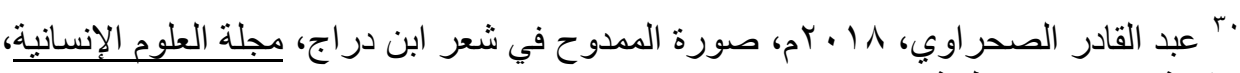

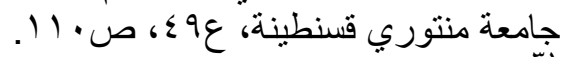

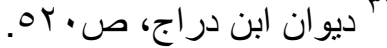




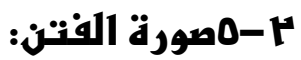

ما إن ثار محمد بن عبد الجبار على الحاجب عبد الرحمن المنصور، إلا وبدأ

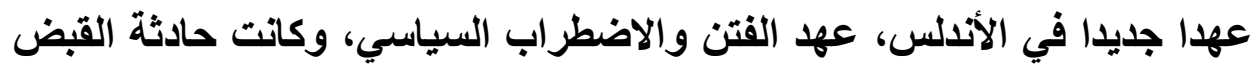
عليه وقتله إيذانا بالعهد الجديد في الأندلس "قال عمر بن أحمد: فضربيته

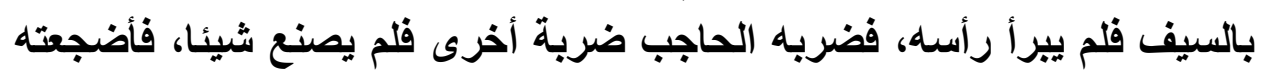

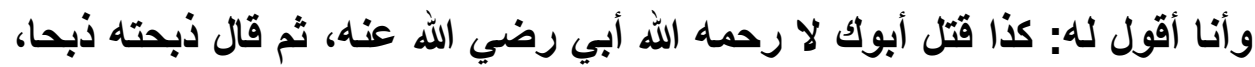

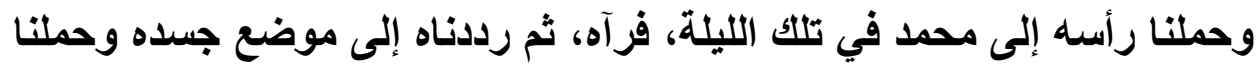

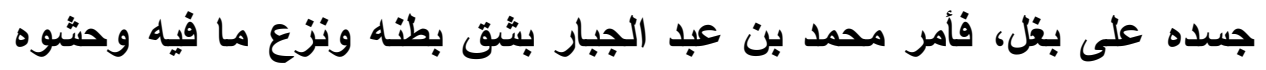

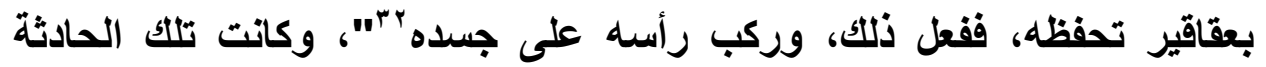

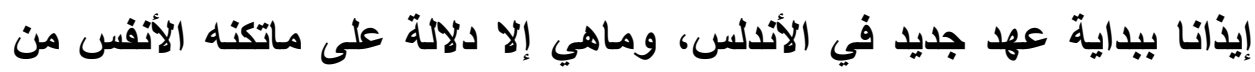

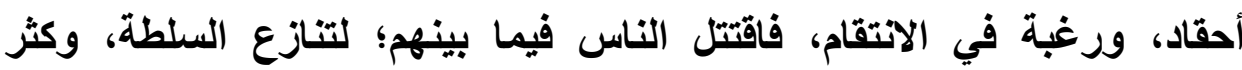
الانتقام، لذلك وصفها ابن دراج بالجاهلية:

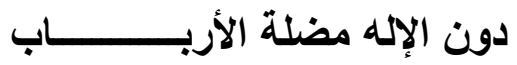

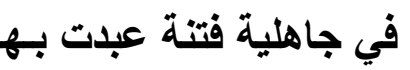

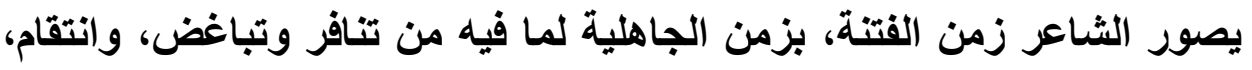

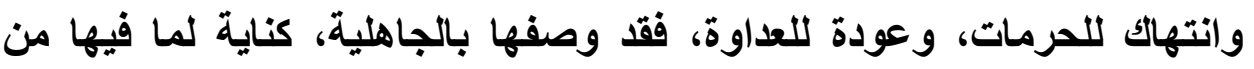
جهل وطيش، وقا أصبح الاحتكام فيها للسيف، والقوة، ما جعل الثاعر يعلن

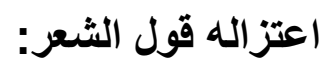

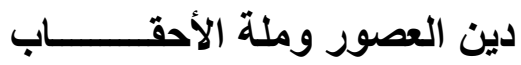
ولأتركن خلودها ونشيده

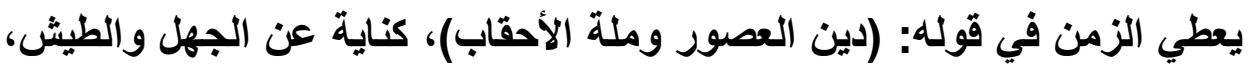

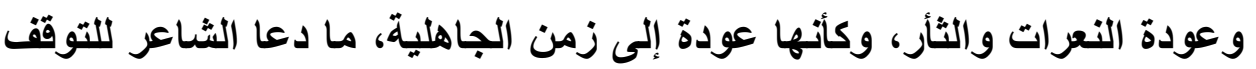

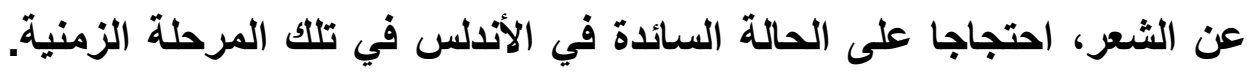
وفي صورة أخرى يصور لنا ابن دراج ذلك المشها المؤلم، مستعينا بالزمن لتوضيح ذلك: وفي صورة

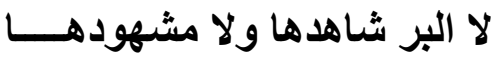

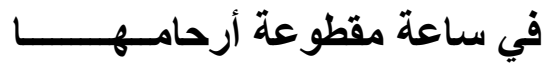
تعطي الصورة المتمثية في قوله: ( في ساعة مقطوعة أرحامها)، كناية عن شدة فئة

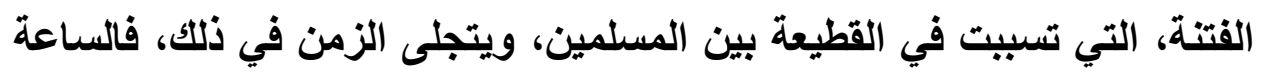

rr 
ليس المقصود بها الوقت المعلوم لمدتها، بل الفترة التي يعيشها الشاعر في تلك المرحلة الزمنية. ويؤكد تلك الصورة في قصيدة أخرى:

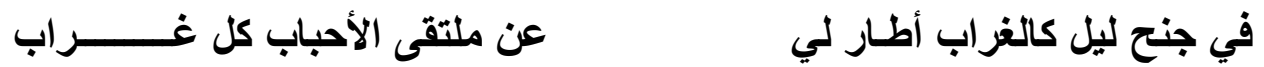
تجتمع الصورة الزمنية، والدلالية؛ لتبين هول تلك الفتن: ( في جنح ليل كالغراب)، فثدة الظلام يشبهها بالغراب، لما للغزاب من دلالة على الثؤم "لأنه

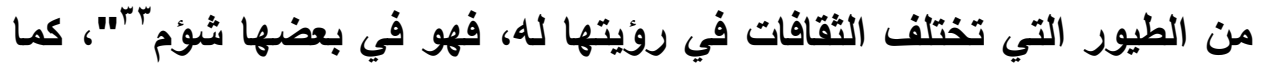
تسبيت تلك القتن في فقد الأحبة: ( عن ملتقى الأحباب كل غراب)، فقد ارتبط

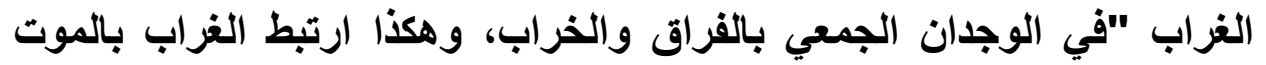

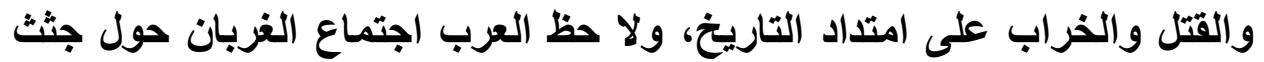

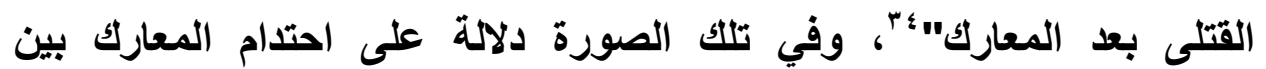

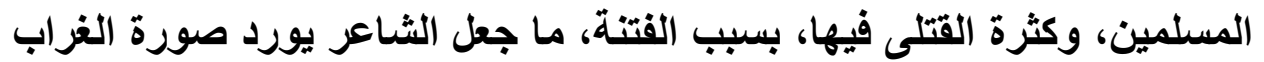
في الشطر الأول، دلالة على شدة الفتنة، وفي الثاتية على كثرة القتلى، وفقد الأحبة "فالثقافة العربية احتفظت للغزاب بصورة سلبية لاقترانه بالفراق والرحيل والاغتراب والموت" "r. وتستمر صورة الطائر في الالالة على الفتنة: أعير ب" له جناح من صباح تعطي صورة الزمن المتمثئة في الصباح والمساء، تصوير لمشهد الفتن، فشبه

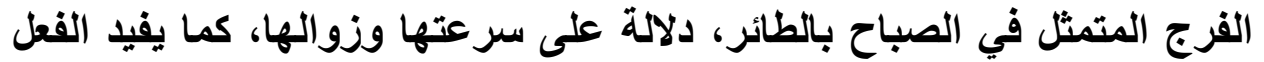

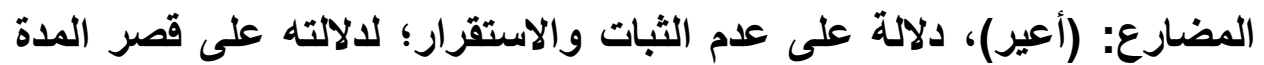

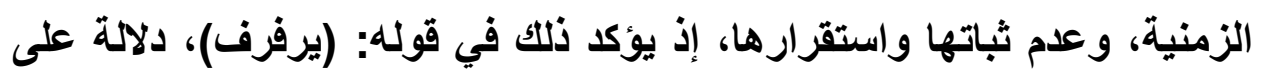
عدم الثبات. وفي صورة أخرى تبين ما فعله الوزير عيسى واتهي:

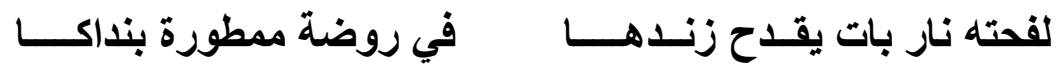

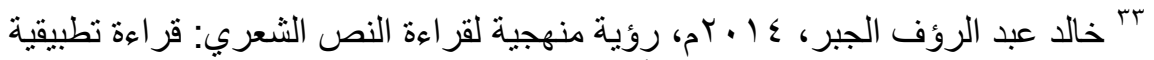

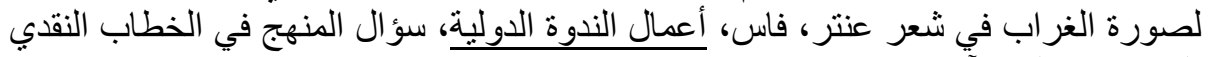

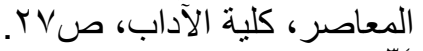

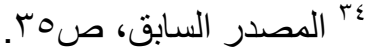

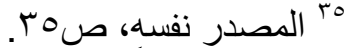
"بr في الديوان، أَغَرُ، وذكر أن في شرح المقصورة، وفي الر ايات: أعبر، و الدلالة تنتاسب أكثر

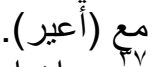

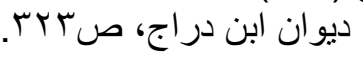




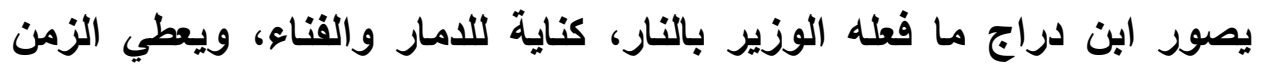

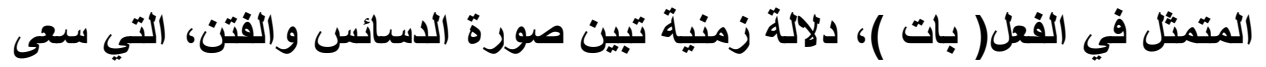

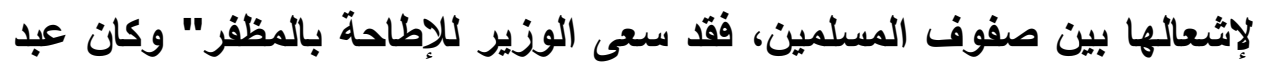

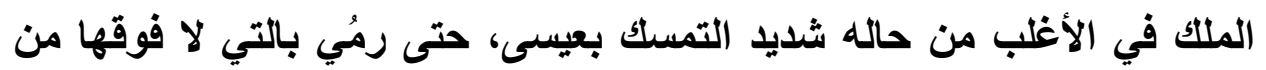

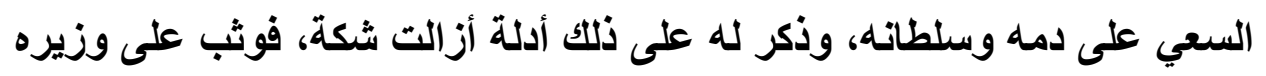

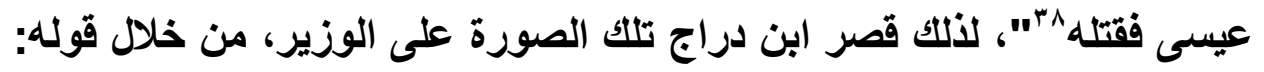
(لفحته)، وفي تصوير آخر لمشاهد تلك الفتن وويلاتها:

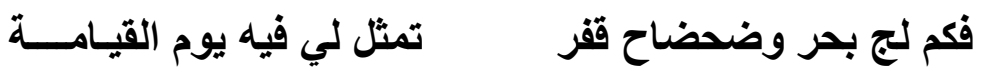

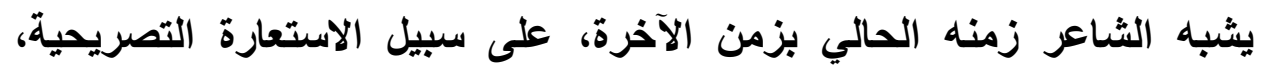

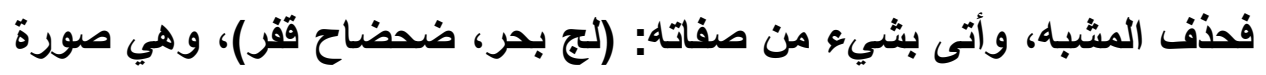

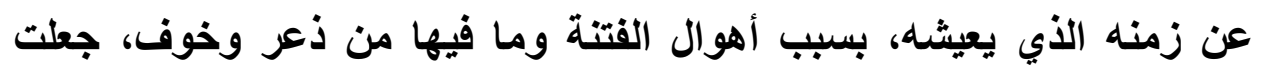
الثاعر يشبهها بيوم القيامة.

r-1- مورة الغربة والألم: عاش ابن دراج استقرار في ظل الدولة الدولة العامرية، إلا أنه شعر بالغربة "فنراه

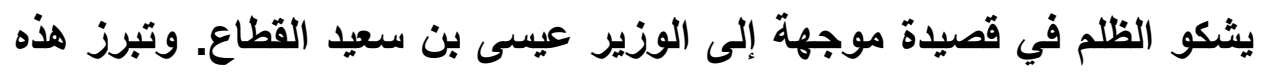

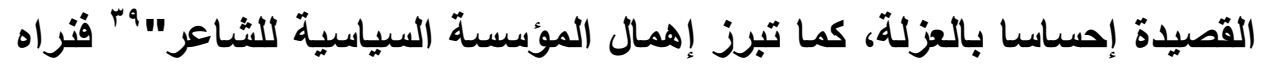
يثكو الوحدة، والثشعور بالغربة، وتخلي الجميع: وزادي من جهاي وراحلتي رجلي

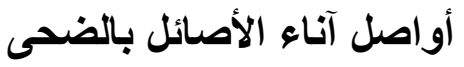

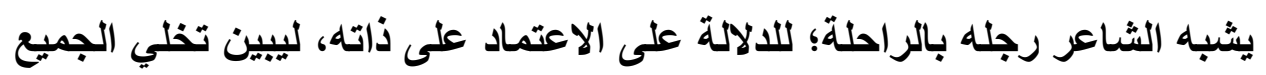

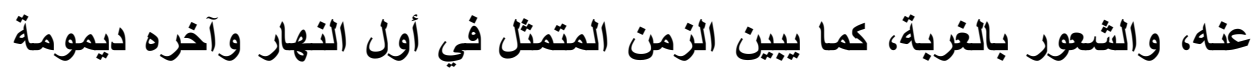

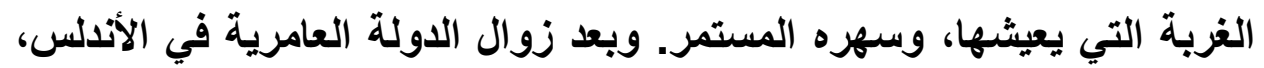

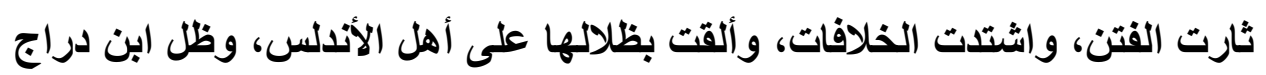

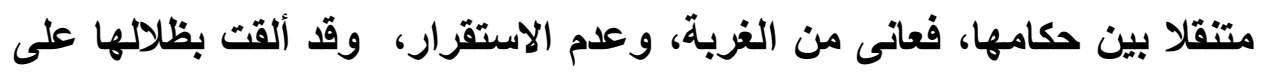

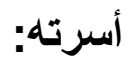
تركََ الحياةَ لنا كأمسِ الأَّا هب في غَولِ ذِي لُجَجِ لَبَسن دياجيـا

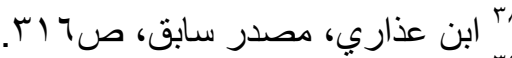

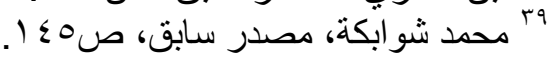




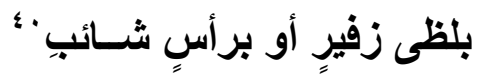

نجلو ظكلامَ الليلِ قبلَ صباحِهِهِ

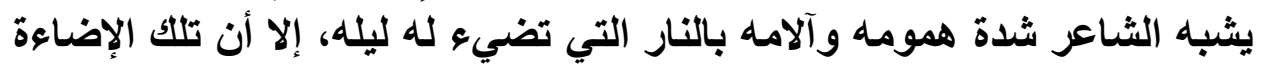

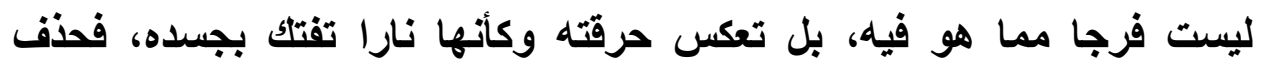
المشبه به وأتى بشيء من صفاته: (لظى)، على سبيل الاستعارة المكنية؛ ليبين معاناته وآلامه. وف قصبدة أخئه أخرى:

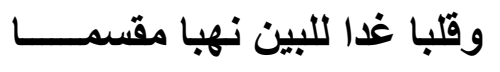

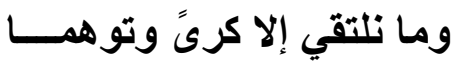

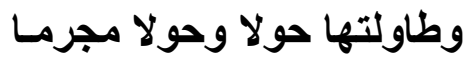

تقسم ريب الدهر والنأي شملنـا

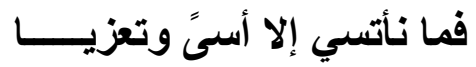
ليالي كالإعدام طولها الأسيس الأسى وتعزي

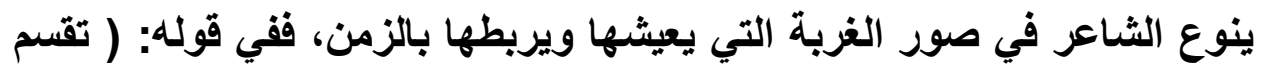

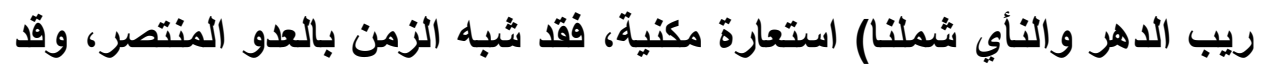

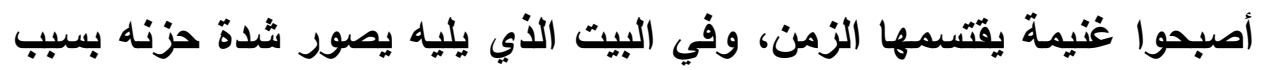

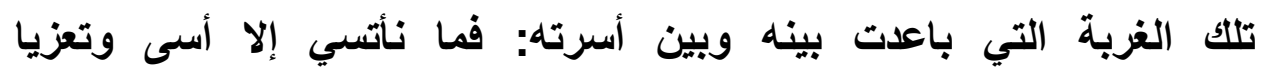

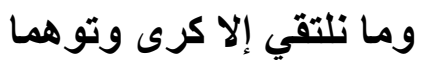
تبين الصورة المجازية حال الشاعر وبعده عن أسرتها، إذ لا لإلتقي بهم إلا من

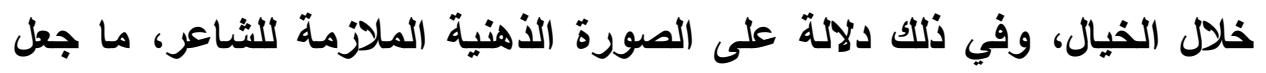

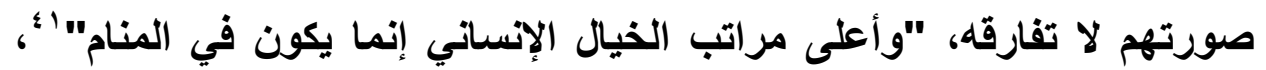

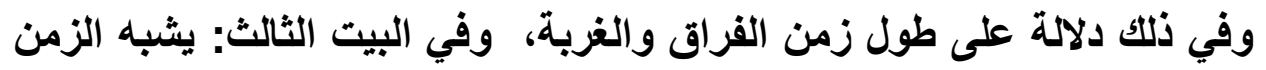

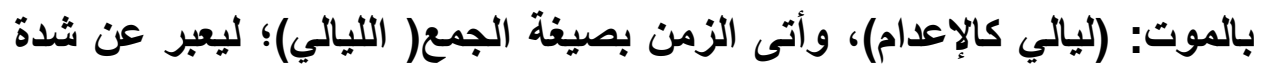

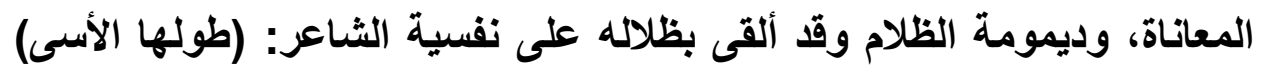
فحزنه مستمر، وقد أصبح ضحية للزمن وكأنه مجرما حكم عليه بالإعدام: (ليالي

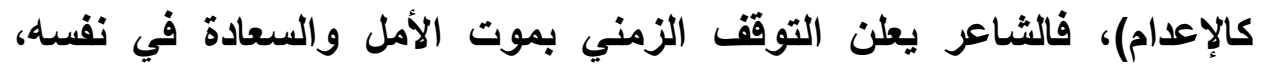
وتستمر غربة الثاعر التي يصور فيها حال أسرتئه:

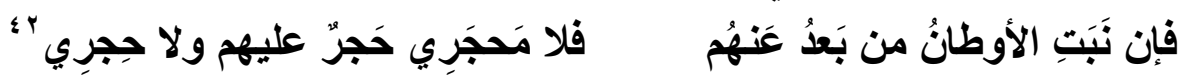

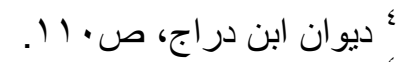

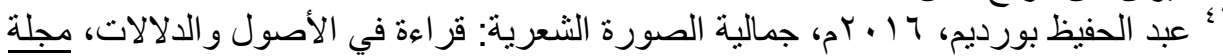

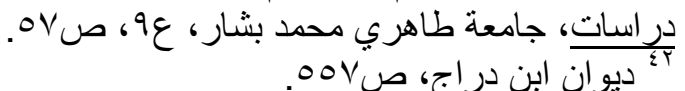


تعطي الصورة المجازية في قوله:(نبت الأوطان)، صورة دقيقة لحالة الثاعر

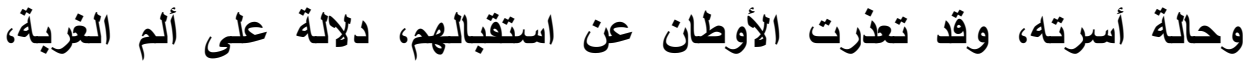

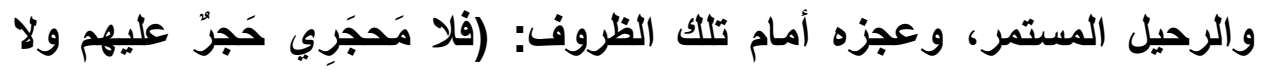

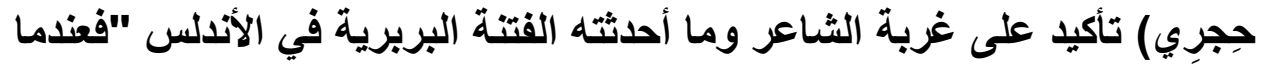

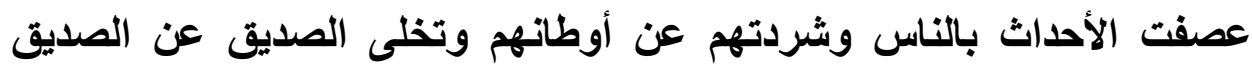

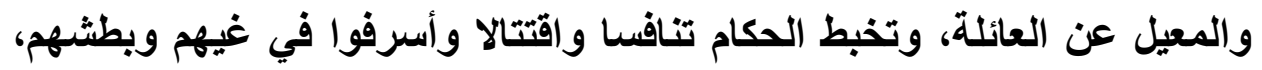

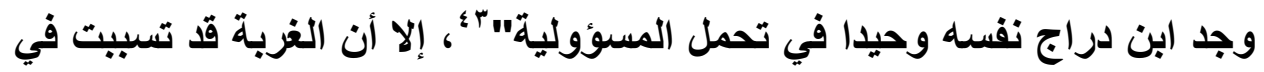
عجزه عن تحمل تلك المسؤولية، ففي قصيدة أخرى يؤكد الضياع، وشدة

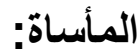

\section{ولا خلة إلا الهجير إذا التظى فكان لهم جمرا وكانوا له شيا} يصور الثاعر حال أسرته وشدة غريتهم، من خلال الصورة المجازية: (ولا خلة

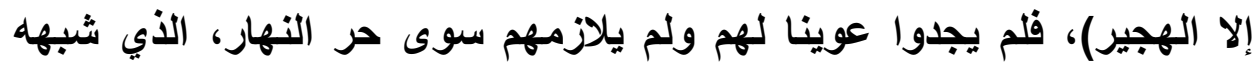

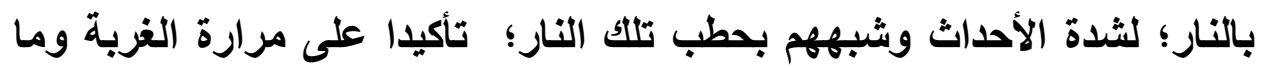

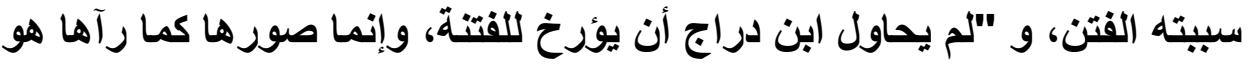

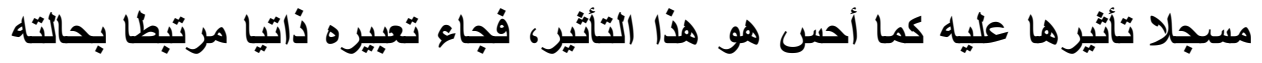

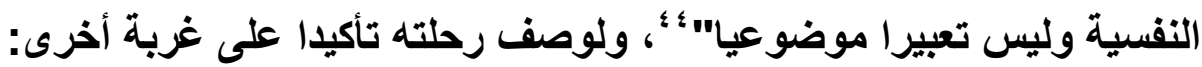

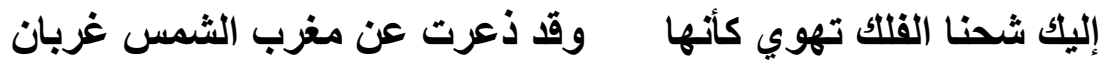

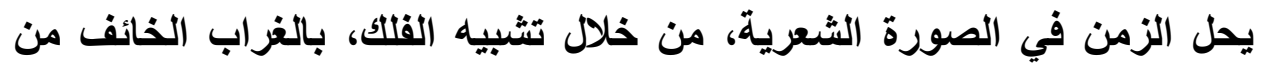

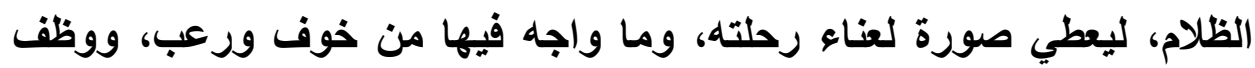

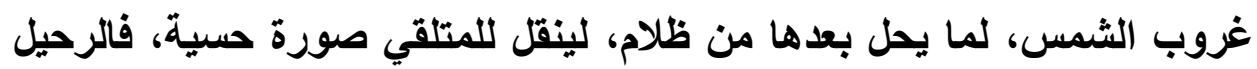

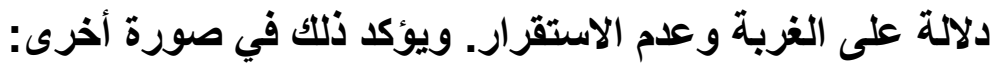

ويوم رحيلنا يوم كعام إمري

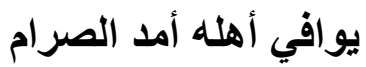

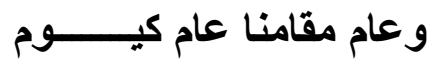

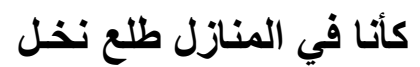

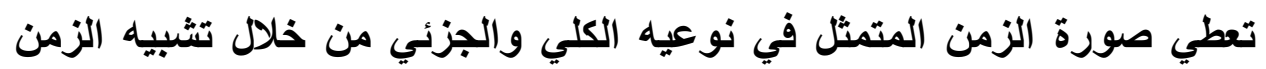

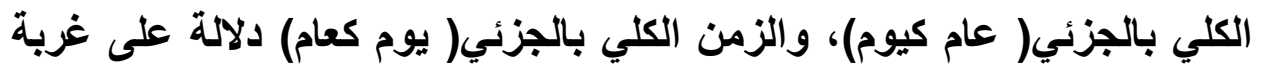

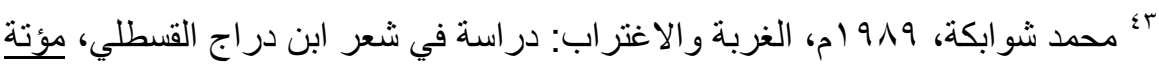

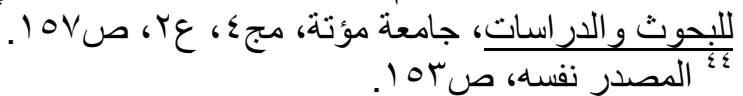


الثاعر وتنقله المستمر، وتعكس ما يختلج في نفسه من ألم، فغربته مستمرة،

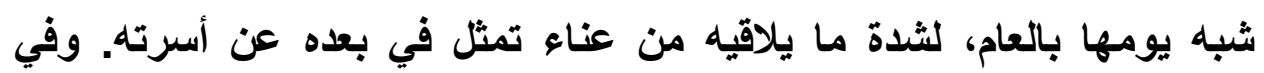
قصيدة أخرى يصرح الثاعر بغربته:

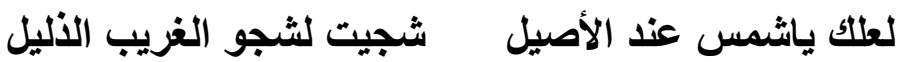

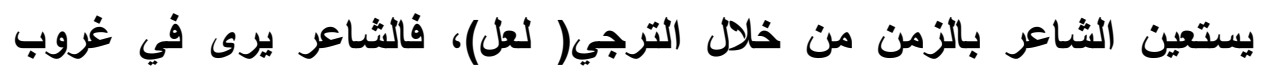

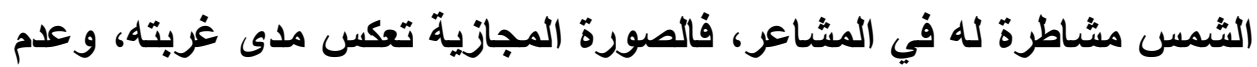

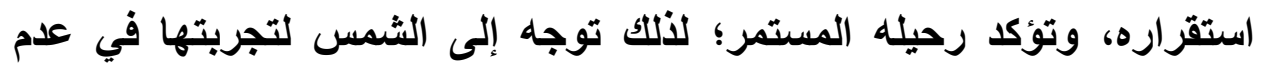
الثبات وديمومة الرحيل.

\section{الخاتمةة:}

وبعد أن وصلنا إلى خاتمة البحث، بفضل الله ومنته، نجمل بعض النتائج فيما يلي:

ا-شكلت صورة الليل رمز القوة والسطوة على الأعداع، إذ يقرنها الشاعر كثيرا بوصف الجيش. r-يبرز الشاعر دور الممدوح من خلال الزمن، فيشبهه بالبدر حينما تشتد الخطوب، وبالشمس، في حالة الاستقرار.

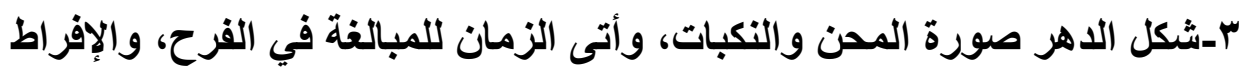

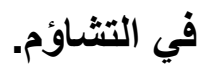




\section{مراجه البهث}

ابن خاقان، مطمح الأنفس ومسرح التأنس في ملح أهل الأندلس، دراسة

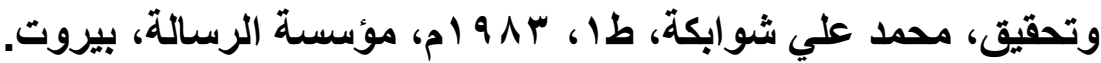

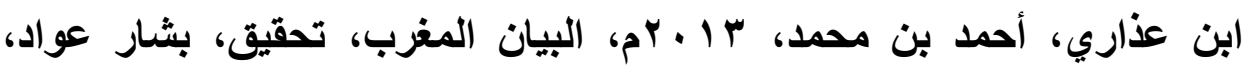

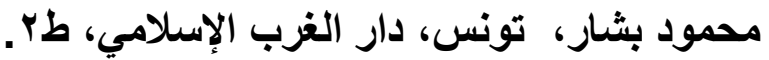

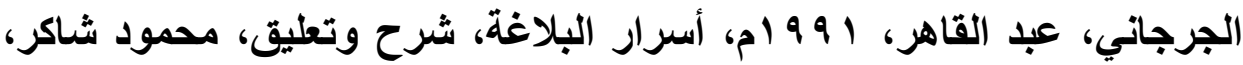

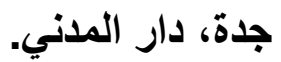
الجرجاني، عبد القاهر، ـ ـ بم، دلائل الإعجاز، شرح، محمد شادي، مصر، دار اليقين. - (الجرجيان

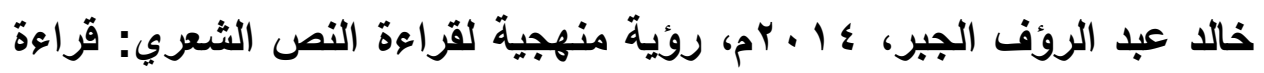
تطبيقية لصورة الغراب في شعر عنتر، فاس، أعمال الندوة الدولية، سؤال

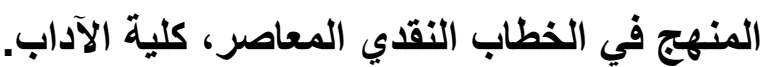
ديوان ابن دراج، تحقيق، محمود علي مكي، طا، الفاب، الابل، 19، منشورات المكتب

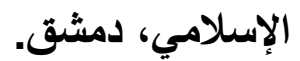
الصعيدي، عبد المتعال، بغية الإيضاح لتلخيص المفتاح، مكتبة الآداب، القاهرة،

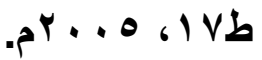

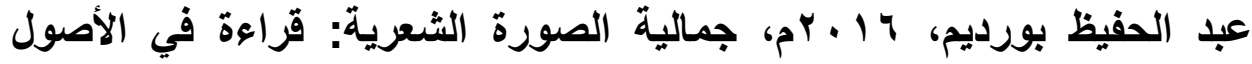

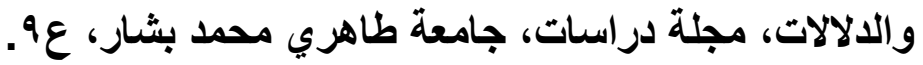
عبد السلام بن عبد الرحمن العوفي، دلالات اسم الفاعل واستعمالاته، مجلة

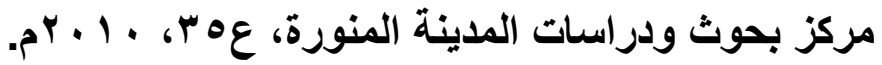

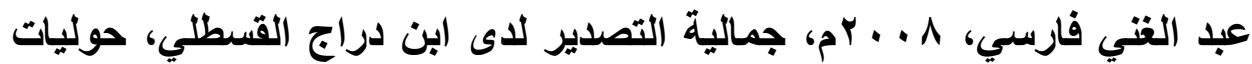

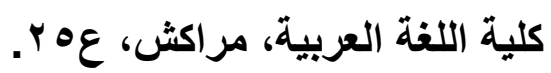

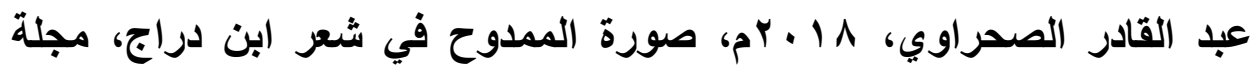
العلوم الإنسانية، جامعة منتوري قسنطينة، ع9 ؛ ؛.

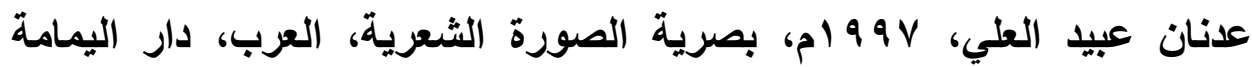

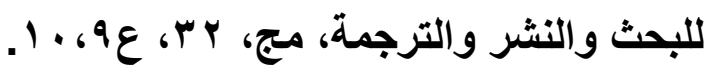
علي علي صبح، الصورة الأدبية تأريخ ونقد، مصر، دار إحياء الكتب المصرية. 
القزويني، الخطيب، 14 إ؛ اهـ، الإيضاح في علوم البلاغة، تحقيق: عبدالقادر

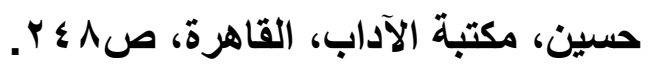

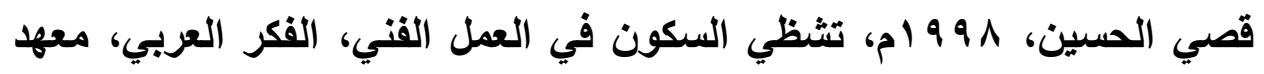

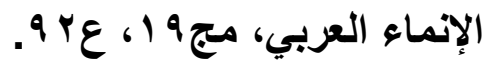

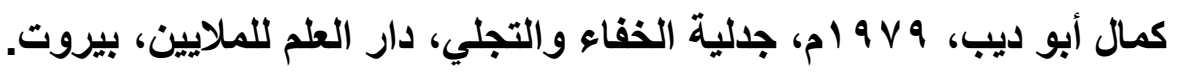

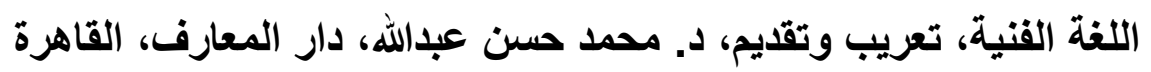

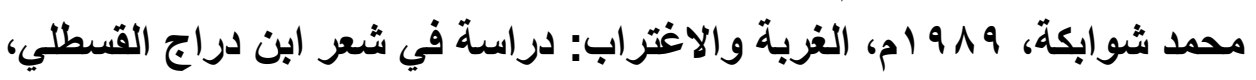

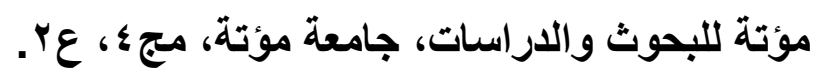

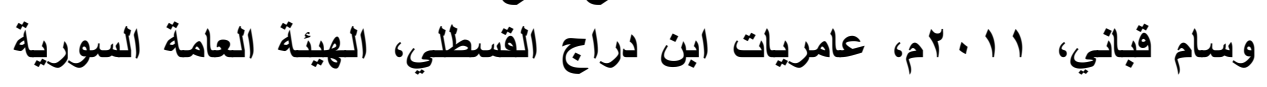

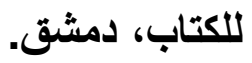

